\title{
Cell-Type-Specific Contributions of Medial Prefrontal Neurons to Flexible Behaviors
}

\author{
낙ofumi Nakayama, Ines Ibañez-Tallon, and ${ }^{-N a t h a n i e l ~ H e i n t z ~}$ \\ Laboratory of Molecular Biology, Rockefeller University, New York, New York 10065
}

Behavioral flexibility and impulse control are necessary for successful execution of adaptive behavior. They are impaired in patients with damage to the prefrontal cortex (PFC) and in some clinically important conditions, such as obsessive-compulsive disorder. Although the medial prefrontal cortex (mPFC) has been investigated as a critical structure for behavioral flexibility and impulse control, the contribution of the underlying pyramidal neuron cell types in the mPFC remained to be understood. Here we show that interneuron-mediated local inactivation of pyramidal neurons in the MPFC of male and female mice induces both premature responses and choice bias, and establish that these impulsive and compulsive responses are modulated independently. Cell-type-specific photoinhibition of pyramidal deep layer corticostriatal or corticothalamic neurons reduces behavioral flexibility without inducing premature responses. Together, our data confirm the role of corticostriatal neurons in behavioral flexibility and demonstrate that flexible behaviors are also modulated by direct projections from deep layer corticothalamic neurons in the MPFC to midline thalamic nuclei.

Key words: corticostriatal; corticothalamic; mouse optogenetics; prefrontal cortex; probabilistic reversal task; pyramidal neuron

\section{Significance Statement}

Behavioral flexibility and impulse control are indispensable for animals to adapt to changes in the environment and often affected in patients with PFC damage and obsessive-compulsive disorder. We used a probabilistic reversal task to dissect the underlying neural circuitry in the MPFC. Through characterization of the three major pyramidal cell types in the MPFC with optogenetic silencing, we demonstrated that corticostriatal and corticothalamic but not corticocortical pyramidal neurons are temporally recruited for behavioral flexibility. Together, our findings confirm the role of corticostriatal projections in cognitive flexibility and identify corticothalamic neurons as equally important for behavioral flexibility.

\section{Introduction}

Behavioral flexibility and impulse control are indispensable for animals to adapt to changes in the environment. Behavioral flexibility refers to the ability to update a response based on the history of previous actions and outcomes, whereas impulse control is defined as the capability to inhibit action at inappropriate timings. These cognitive processes are controlled by the PFC (Robbins, 1996; Miller and Cohen, 2001; Cools and Robbins,

\footnotetext{
Received Dec. 15, 2017; revised March 12, 2018; accepted April 3, 2018.

Author contributions: H.N. and N.H. designed research; H.N. performed research; H.N., I.I.-T., and N.H. analyzed data; H.N., I.I.-T., and N.H. wrote the paper.

This work was supported by the Howard Hughes Medical Institute, National Institutes of Health/National Institute on Drug Abuse Grant 1P30 DA035756-01, the Leon Black Family Foundation, the Rockefeller University Kavli Neural Systems Institute, and the Nakajima Foundation. We thank Jie Xing for skilled assistance; and Laura Kus and Hiroshi Abe for helpful suggestions.

The authors declare no competing financial interests.

Correspondence should be addressed to Dr. Nathaniel Heintz, Laboratory of Molecular Biology, Rockefeller University, 1230 York Avenue, New York, NY 10065. E-mail: heintz@rockefeller.edu.

H. Nakayama's present address: Neuroscience Institute, Langone Medical Center, New York University, New York, NY 10016.

DOI:10.1523/JNEUROSCI.3537-17.2018

Copyright $\odot 2018$ the authors $\quad 0270-6474 / 18 / 384490-15 \$ 15.00 / 0$
}

2004) and altered in several neuropsychiatric disorders, including obsessive-compulsive disorder (OCD) and attention deficit hyperactivity disorder (Schachar et al., 1995; Chamberlain et al., 2005; Remijnse et al., 2006). Neuropsychological and neuroimaging studies have allowed association of the degree of cortical damage with performance on cognitive tasks (i.e., the set-shifting task for cognitive flexibility and the stop-signal task for impulsive control) (Cools et al., 2002; Aron et al., 2003; Chamberlain et al., 2006). Furthermore, neuroimaging studies in patients with OCD (Menzies et al., 2008), attention deficit hyperactivity disorder (Winstanley et al., 2006), and substance abuse (Jentsch and Taylor, 1999) suggest that overlapping executive functions are affected in these disorders.

Among the substructures in the PFC, the mPFC has recently emerged as a critical hub for behavioral flexibility and impulse control. Contributions of the $\mathrm{mPFC}$ and its substructures to goaldirected behaviors and rapid behavioral adaptation to changing action-outcome relationships have been studied extensively in primates and rodents (Izquierdo et al., 2004; Ostlund and Balleine, 2005; Kennerley et al., 2006; Rushworth and Behrens, 2008; Buckley et al., 2009; Karlsson et al., 2012; Rodgers and DeWeese, 
2014; Tervo et al., 2014; Schuck et al., 2015; Jackson et al., 2016). Lesions of the prelimbic (PL) and infralimbic (IL) subdivisions of the $\mathrm{MPFC}$ in rats have opposing effects on the balance between goal-directed and habitual behaviors (Killcross and Coutureau, 2003; Vidal-Gonzalez et al., 2006; Peters et al., 2009). The imbalance between goal-directed and habitual behavior is also observed in OCD patients (Gillan and Robbins, 2014). Furthermore, the frequency of innate habitual motor programs, such as grooming in rodents, increases with repeated hyperstimulation of the ventromedial orbitofrontal cortex (Ahmari et al., 2013). In contrast, acute photostimulation of the lateral OFC in a mouse model of OCD (Sapap3 mice) rescued maladaptive grooming (Burguière et al., 2013). These studies strongly implicate the contribution of mPFC and other PFC regions to flexible behavioral responses.

Impulsivity is defined as the inability to inhibit inappropriate actions or the inability to wait for the outcome (Dalley et al., 2011). Response inhibition, as a measure of impulsivity, is modeled by the frequency of premature responses in a choice task, such as the 5-choice serial reaction time task (Chudasama et al., 2003; Kobayashi et al., 2013). Rats with IL lesions showed increased impulsivity in the 5-choice serial reaction time task (Chudasama et al., 2003). Increased impulsivity is also observed in patients with drug abuse. Patients with chronic methamphetamine abuse showed deficits in stop-signal task, another behavior task to assess motor inhibition (Jentsch and Taylor, 1999; Monterosso et al., 2005). Given the abnormalities of PFC circuitry evident in drug addicts (Sekine et al., 2003), these behavioral studies also suggest a contribution of the mPFC to impulse control.

Although previous studies have established that both behavioral flexibility and impulse control require intact $\mathrm{mPFC}$ function, the underlying neural circuits regulating each of these processes remained to be fully understood. To enable genetic dissection of mPFC circuits controlling behavioral flexibility and impulse control, we have performed cell type-specific optogenetic inactivation in mice during a behavioral task that allows investigation of impulsivity and flexibility in a temporally restricted manner. We have used a series of Cre driver lines targeting specific neuron types in the mPFC (Gong et al., 2007; Gerfen et al., 2013) to determine the contributions of distinct cell populations in the mPFC to these behaviors.

\section{Materials and Methods}

Animals. All procedures were approved by the Rockefeller University Institutional Animal Care and Use Committee. All mice used in the current study were bred to C57BL/6J for at least 7 generations. Colgalt2Cre (NF111), Syt6-Cre (KI109), and Sepw1-Cre (NP39) lines were generated by the GENSAT project and maintained at Rockefeller University. VGAT-ChR2-EYFP line (Jax Stock \#014548) (Zhao et al., 2011) was obtained from The Jackson Laboratory. A total of 61 male mice and 7 female mice were used. Mice were at least 6 weeks old at the time of surgery.

Surgery and virus injections. A mixture of ketamine (100 mg) and xylazine ( $1 \mathrm{mg}$ ) was used for anesthesia. For characterization of Cre mouse lines, either AAV2.9-CAG-FLEX-ArchT-GFP (Han et al., 2011) (UNC Vector Core) or AAV2.9-FLEX-L10GFP were injected unilaterally (anteroposterior 1.9-2.0, mediolateral 0.5, dorsoventral -1.6) using a syringe (7647-01, Hamilton) with a glass pipette. For behavioral experiments, AAV2.9-CAG-FLEX-ArchT-GFP virus was injected bilaterally into the mPFC of Colgalt2-Cre (NF111), Syt6-Cre (KI109), and Sepw1Cre (NP39) (anteroposterior: 1.75, 2.15; mediolateral: \pm 0.5 ; dorsoventral: $-1.6 \mathrm{~mm}$ from bregma). Following AAV2.9-FLEX-ArchT virus injection in the three Cre lines, fiberoptic cannulas (CFML12L02, Thorlabs) were implanted bilaterally (anteroposterior 1.95, mediolateral \pm 0.5 , dorsoventral $-1.0 \mathrm{~mm}$ from bregma). For VGAT-ChR2 animals, fiberoptic cannulas were implanted in the same location without virus injection. For inactivation of axon terminals in Colgalt2-Cre mice, fiberoptic cannulas were implanted in the dorsal striatum (anteroposterior 1.0 , mediolateral \pm 1.1 , dorsoventral -2.2 ).

Behavioral training procedures. The probabilistic reversal task was performed in an operant chamber (ENV-307A, Med Associates) with a stainless-steel grid floor, illuminated using house light. The operant chamber was placed in a sound and light-attenuating cubicle equipped with a fan for ventilation providing background noise. A nose-port (ENV-313M, Med Associates) was placed in the center of one wall, and two choice ports (custom made with 3D printing) were placed on the left and right sides of the center nose-port. The choice ports were connected with a food pellet dispenser (ENV-203-14P, Med Associates) that released $14 \mathrm{mg}$ food pellets (F05684 BioServ). A tone generator (ENV323AM, Med Associates) and a click sound generator (ENV-135M, Med Associates) were used to provide auditory feedback for outcome delivery. After recovery from surgery, animals were food restricted to gradually decrease body weight. During food restriction, animals were habituated to the smaller food pellets used for behavioral experiments to familiarize animals. Once the body weight reached $80 \%-90 \%$ of their free-feeding body weight, behavioral training started.

Mice were trained to initiate a trial by poking into the center port when the LED light in the center port was turned on (Initiation cue). When the mice poked into either of the side choice ports in the presence of the initiation cue, the entry was counted as premature response and was followed by $3 \mathrm{~s}$ timeout and $1.5 \mathrm{~s}$ intertrial interval. The same trial was repeated after time-out and intertrial interval. The time-out and intertrial interval was also followed after $20 \mathrm{~s}$ of no responses. Following the initiation poke, LED lights on both left and right ports were turned on, and mice were allowed to freely make a choice between the two peripheral ports. In each trial, one side was assigned as the correct choice and the other side as the incorrect choice. Correct choices were followed by delivery of a food pellet at $75 \%$ of probability, whereas incorrect choices were never rewarded. Food pellet delivery was coupled with a tone while lack of reward in both correct and incorrect trials was followed by a click sound. The side of correct and incorrect choices was fixed in consecutive trials, and it was reversed when mice reached a behavioral criterion. After mice had achieved $80 \%$ or more choice accuracy, the reversal occurred randomly at any of the subsequent trials at $15 \%$ probability. Once the reversal happened, the position of correct and incorrect sides was fixed until mice meet the criterion again. Notably, illumination of LED lights in both choice ports signaled availability of choice but did not indicate which side was the correct choice. Thus, the mouse had to optimize its decision based on the choice and outcome history. The behavioral session was terminated after $60 \mathrm{~min}$ from the start.

Optogenetic perturbation of neural activity. Photoactivation experiments of cortical interneurons in VGAT-ChR2 mice expressing the lightsensitive cation conducting opsin, channelrhodopsin-2 (ChR2) in GABAergic interneurons were performed using $\lambda=473 \mathrm{~nm}$ blue light at $4-5 \mathrm{~mW}$ laser power at the fiber tip and trains of $5 \mathrm{~ms}$ pulses delivered at $40 \mathrm{~Hz}$ frequency. Similar conditions: $\lambda=473 \mathrm{~nm}$, frequency $=40 \mathrm{~Hz}$, but lower laser power $(1.5 \mathrm{~mW})$ have been reported to result in $87 \% \pm$ $3 \%$ activity reduction of cortical pyramidal neurons in a region with a radius of $\sim 1 \mathrm{~mm}$ extending all cortical layers (Guo et al., 2014). Photoinhibition experiments of cortical pyramidal neurons in mice expressing the light-driven outward proton pump, archaerhodopsin-3 (ArchT) were performed using continuous green light $(\lambda=532 \mathrm{~nm})$ delivered at $10 \mathrm{~mW}$ laser power. The same laser power and wavelength have been shown to inactivate cortical pyramidal neurons in multielectrode array recordings in vivo (Bukalo et al., 2015).

Blue or green light was delivered at three different time periods, including the pre-start, pre-choice, and post-choice periods, and the laser was delivered at each time period in a random subset of $10 \%$ of trials. In pre-start trials, the laser was turned on at the onset of initiation cue and turned off at the initiation poke. If premature responses occurred during pre-start trials, the light was turned off during time-out, and the pre-start trial was repeated. In pre-choice inactivation trials, laser was turned on at the initiation poke and turned off at the choice poke. In post-choice trials, the laser was turned on during choice and lasted for $3 \mathrm{~s}$. Mice were 
tested for 10 sessions with photostimulation (except one animal with 8 sessions; see Fig. 7D-F).

Histology. After behavioral experiments, animals were deeply anesthetized and transcardially perfused with 4\% PFA in PBS. Dissected brains were placed in $4 \%$ PFA/PBS solutions overnight for postfixation and transferred to $30 \%$ sucrose solution. Once brains sunk to the bottom of the tube, they were embedded in OCT compound, and $35 \mu \mathrm{m}$ freefloating coronal sections were prepared on a cryostat.

For immunohistochemistry, free-floating sections were blocked with $5 \%$ normal goat serum and $0.25 \%$ Triton X-100 in PBS. Sections were incubated with an anti-GFP antibody (1:1000, chicken polyclonal, ab13970, Abcam) overnight at room temperature. The next day, sections were rinsed with PBS three times for 5 min and incubated with a secondary antibody conjugated with AlexaFluor- 488 dye (1:500, goat antichicken IgG, A-11039, Invitrogen) for $90 \mathrm{~min}$. After rinsing with PBS three times, sections were mounted on slides and coverslipped with mounting medium (ProLong Gold Antifade Reagent with DAPI, P-36931, Invitrogen). Images were acquired with a confocal microscope.

Experimental design and statistics. The design of behavioral paradigm was adapted from Tai et al. (2012) and Parker et al. (2016). The number of animals for each group (8-12 mice) was chosen in accord with previous studies in mice using similar paradigms. All animals received three optogenetic manipulation types along with laser off trials to enable paired statistical test as described below.

Statistical analyses were performed using MATLAB (The MathWorks). In general, we assessed the effect of the optogenetic manipulation by comparing behavioral performance of laser off and laser on trials within the same experimental groups. The trial structure of the behavioral task was designed so that individual animals experience all stimulation types. Because there was no assumption about normal distribution of behavioral readouts, paired nonparametric statistics (Wilcoxon signed rank test) were used. In case multiple comparisons were performed, $p$ values were corrected using Bonferroni's method.

To calculate the premature response ratio, the number of premature responses was divided by the number trials. The premature response ratio calculated for each inactivation condition was compared with that of laser off condition using Wilcoxon signed-rank test. For Figure 4, premature responses for the two choice ports were counted separately and grouped based on the side corresponding with higher choice probability in each condition. Three comparisons (Laser OFF vs pre-start in biased side, Laser OFF vs pre-start in anti-biased side, and biased side vs anti-biased side in pre-start inactivation) were performed for each panel in Figure 4 using Wilcoxon signed-rank test. $p$ values were corrected with Bonferroni's method.

The choice bias index for each animal was calculated using the following equation.

$$
\text { Choice bias index }=\mid \text { ChoiceP }(\mathrm{L})-\text { ChoiceP(R) } \mid
$$

Where ChoiceP(L) and ChoiceP(R) represent the choice probability of left and right choice, respectively. The choice bias index tends to have larger values because of the sampling bias when it is calculated from data with small number of trials. To avoid the effect of difference in the number of trials, the bias index of laser off condition was calculated using 1/7 of laser off trials randomly sampled from each behavioral session so that approximate the number of trials for each condition became the same. The sampling was performed 500 times, and the mean of the calculated choice bias index was used as that of the laser off condition. The bias index for each inactivation condition was compared with that of the laser off condition using Wilcoxon signed-rank test. $p$ values were corrected with Bonferroni's method based on the number of multiple comparisons.

The contribution of the previous choice and outcome to subsequent choices was analyzed with the following logistic regression model:

$$
\begin{aligned}
& \log \left(\frac{P(i)}{1-P(i)}\right)=\sum_{j=1}^{n}\left(a_{j} * R(i-j)+b_{j} * N(i-j)\right) \\
& +\sum_{j=1}^{n}\left(c_{j} * R(i-j)+d_{j} * N(i-j)\right) * X 1(i-j)
\end{aligned}
$$

$$
\begin{aligned}
& +\sum_{j=1}^{n}\left(e_{j} * R(i-j)+f_{j} * N(i-j)\right) * X 2(i-j) \\
& +\sum_{j=1}^{n}\left(g_{j} * R(i-j)+h_{j} * N(i-j)\right) * X 3(i-j) \\
& + \text { Bias }(\text { OFF })+\text { Bias }(\text { Pre-start }) * X 1(i) \\
& + \text { Bias }(\text { Pre-choice }) * X 2(i)+\text { Bias }(\text { Post-choice }) * X 3(i-1)
\end{aligned}
$$

where $P(i)$ represents the probability of choosing the left choice on trial $-(i) . R(i-j)$ represents the independent variable for a rewarded outcome at trial $(i-j)$ (1 for left rewarded trials, -1 for right rewarded trials, and 0 for unrewarded trials). $N(i-j)$ represents the independent variable for an unrewarded outcome at trial $(i-j)(1$ for left unrewarded trials, -1 for right unrewarded trials, and 0 for rewarded trials). $X 1(i)$, $X 2(i)$, and $X 3(i)$ represent the inactivation type of trial $-(i) . X 1(i)$ is 1 for pre-start trials, $X 2(i)$ is 1 for pre-choice trials, $X 3(i)$ is 1 for post-choice trials; each variable is 0 for all other conditions. Regression coefficients were calculated for each animal by concatenating data for 10 sessions using MATLAB (glmfit function). Regression coefficients $a_{j}$ and $b_{j}$ represent regression coefficients for laser-off rewarded and unrewarded choices. $c_{j}-h_{j}$ represent regression coefficients for interaction terms for choices $X$ stimulation. These coefficients for interaction terms were added to $a_{j}$ or $b_{j}$ to obtain the contribution of rewarded or unrewarded choices in inactivation trials $\left(a_{j}+e_{j}\right.$ for rewarded choices of pre-choice inactivation trials). These values were compared with corresponding coefficients of the laser off condition using Wilcoxon signed-rank test. $p$ values were corrected using the Bonferroni's method. The means of regression coefficients across animals were plotted in Fig. $3 B$. In the calculation of bias terms, the average across animals was calculated after taking the absolute value for each animal to treat left side bias and right side bias in the same way.

\section{Results}

To study behavioral flexibility and impulse control, we trained mice to perform the probabilistic reversal task, a binary choice task that requires frequent adjustment of behavior (Chamberlain et al., 2006; Remijnse et al., 2006; Tai et al., 2012; Parker et al., 2016) (Fig. 1A). Briefly, the task required mice to initiate a trial with a nose poke into a central port followed by movement to the left or right port to obtain reward. In each trial, one side was assigned as correct choice, and the other as incorrect choice. Correct choices were followed by delivery of a food pellet with $75 \%$ of probability, whereas incorrect choices were not rewarded. LED light illumination of both choice ports signaled availability of choice but did not indicate which side was the correct choice. Thus, mice were required to optimize their decision based on the choice and outcome history. When choice accuracy in the past 10 trials reached $80 \%$, the location of the rewarded port was switched to the other side at $15 \%$ probability at the beginning of each trial. Reversals and stochastic reward delivery encouraged mice to flexibly adjust choice and prevented them from using a simple response strategy to obtain the reward. After initial training, mice consistently performed the task and experienced multiple reversals during each daily session (155.2 \pm 1.6 trials, $5.5 \pm$ 0.1 reversals per session) (Fig. $1 A$ ). Choice accuracy dropped at reversal and gradually recovered over trials following reversal (Fig. 1B). Mice spent on average $24.5 \pm 0.3$ (left correct blocks) and $24.8 \pm 0.3$ (right correct blocks) trials ( \pm SEM, $n=68$ mice) to switch their behavioral responses following reversal. When we analyzed the effects of reward history in the previous two trials on upcoming choice, mice flexibly adjusted their choice based on the recent outcome following a win-stay, lose-shift strategy (Fig. 1C; 
A
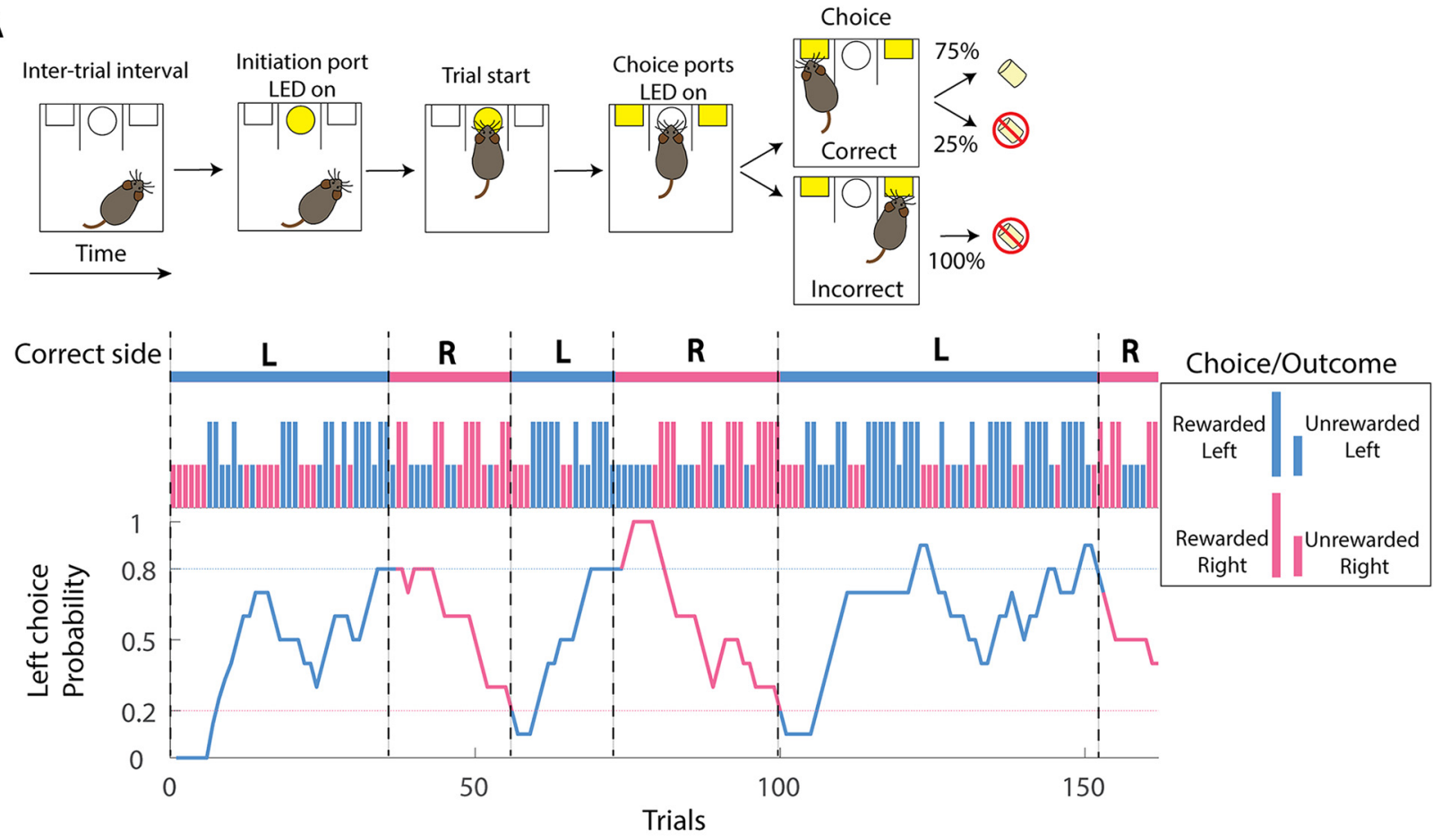

B

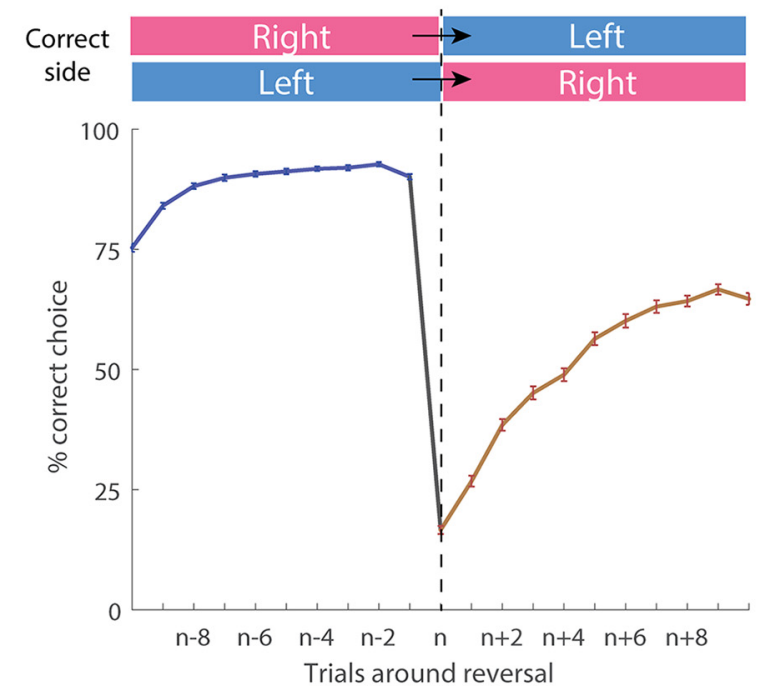

D

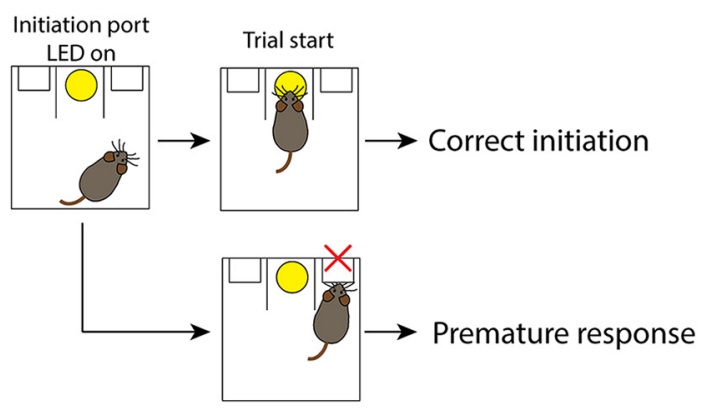

C

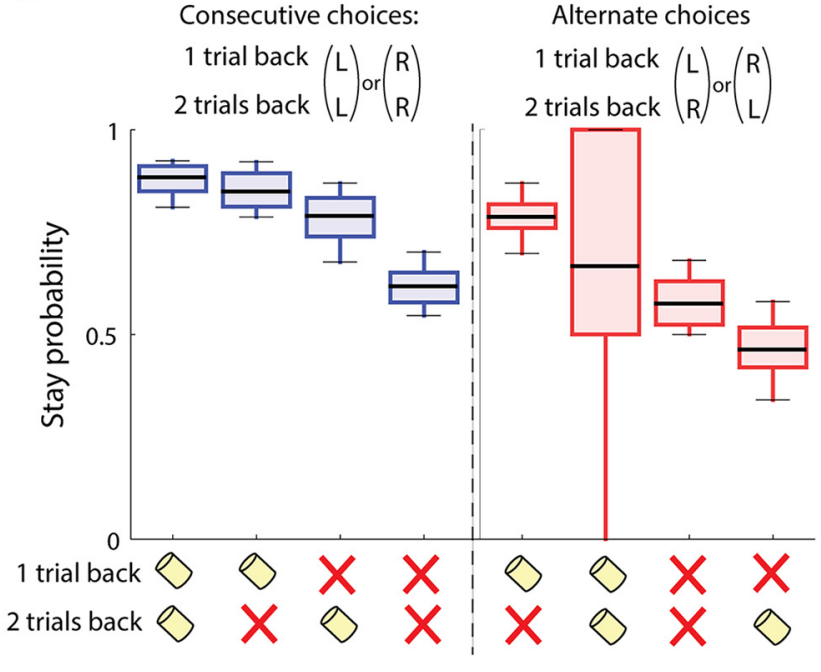

Number of premature responses per trial

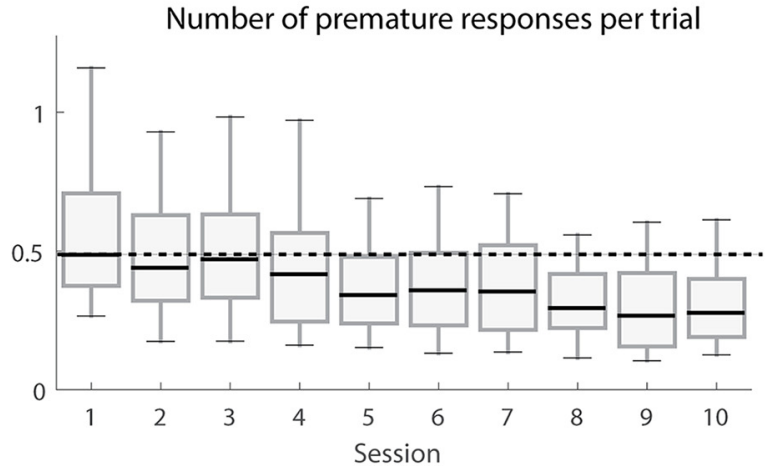

Figure 1. Design of probabilistic reversal task and baseline behavioral performance. $A$, Top, Sequence of events in the probabilistic reversal task. After an intertrial interval, the LED light on the center port was turned on (Initiation cue), and mice initiated a trial by poking the center port (Trial start). Subsequently, LED lights in both left and right ports were turned on, and mice freely made a choice between the two peripheral ports (Choice). Correct choices were followed by delivery of a food pellet at $75 \%$ probability, whereas incorrect choices were never rewarded. Bottom, Performance in an example session of 6 trial blocks. Top, Magenta represents right reward blocks. (yan represents left reward block. Long ticks indicate rewarded trials. Short ticks indicate unrewarded trials. Left choice probability for each trial was calculated from the number of left choices in the recent 10 trials. $\boldsymbol{B}$, Choice accuracy around reversal: (Figure legend continues.) 
$n=68$ mice, consecutive choices; main effect of outcome type, $\chi_{(3)}^{2}=182.56, p=2.5 \mathrm{e}-39$, alternate choices; main effect of outcome type, $\chi_{(3)}^{2}=121.83, p=3.1 \mathrm{e}-26$, Kruskal-Wallis test). These results indicated that mice continuously learned to track the local and global changes in the choice-outcome relationship. We also monitored premature responses during the probabilistic reversal task, by measuring the number of entries to the choice port without previously poking in the center port. A decreasing trend in the frequency of premature responses in consecutive sessions indicated that mice were actively suppressing the natural tendency to respond as they became proficient in the task (Fig. $1 D ; n=68$ mice, main effect of session, $\chi_{(9)}^{2}=75.66, p=1.2 \mathrm{e}-12$, Kruskal-Wallis test).

\section{Interneuron-mediated local inactivation of mPFC pyramidal neurons induces premature responses and choice bias}

To investigate the contribution of the $\mathrm{MPFC}$ to flexible choice behavior, we used VGAT-ChR2-EYFP transgenic mice, previously used for precise inactivation of small volumes of cortical tissue by photostimulation of ChR2 in GABAergic interneurons (Zhao et al., 2011; Guo et al., 2014). We bilaterally implanted optical fibers in the mPFC of these mice (Fig. 2A) for blue light $(\lambda=473 \mathrm{~nm}$ ) laser photostimulation at $4-5 \mathrm{~mW}$ laser power. Based on the location of the tip of the optical fibers in 12 mice, we estimated the area receiving photoinhibition using the model by Stujenske et al. (2015) (Fig. 2-1 B, available at https://doi.org/10. 1523/JNEUROSCI.3537-17.2018.f2-1). These analyses indicated that the majority of cortical layers in the $\mathrm{mPFC}(<1 \mathrm{~mm})$ received light intensity $>1 \mathrm{~mW} / \mathrm{mm}^{2}$ (Fig. 2-1 $\mathrm{A}$, available at https://doi.org/10.1523/JNEUROSCI.3537-17.2018.f2-1). Because cortical interneurons have dense local axonal arbors, and ChR2-mediated photoactivation at moderate laser powers (1.5 $\mathrm{mW}$ ) has been shown to produce potent and local inhibition of cortical pyramidal neurons within $1 \mathrm{~mm}$ radius of the photostimulus center (Guo et al., 2014), we conclude that the higher laser intensity and deeper location of the optical fibers used in our studies produced sufficient photostimulation of interneurons for inactivation (photoinhibition) of the majority of pyramidal neurons within the mPFC. To dissociate cognitive processes that occur at different times during the probabilistic reversal task, we conducted photoinhibition during three different time windows (Fig. 2A): the pre-start period (magenta) during the initiation cue; the pre-choice period (cyan) from initiation poke to the left or right choice port entry; and the post-choice period (yellow) $0-3 \mathrm{~s}$ following choice. Stimulation trials were interspersed with nonstimulation trials to allow within-subject comparisons to determine the effect of photoinhibition.

We first analyzed the ability of mice to successfully initiate the task in response to mPFC inactivation. We quantified the success

\section{$\leftarrow$}

(Figure legend continued.) when mice achieved $\geq 80 \%$ choice accuracy in the past 10 trials, the location of the correct side was switched to the other side at $15 \%$ probability at the beginning of each trial. C, Stay probability after two consecutive choices to the same peripheral port (blue boxes) or to alternate ports (red boxes). Horizontal black bars inside boxes represent medians. Food reward or no reward in the previous two trials are indicated below the graphs. $n=68$ mice, consecutive choices; main effect of outcome type, $\chi_{(3)}^{2}=182.56, p=2.5 \mathrm{e}-39$, alternate choices; main effect of outcome type, $\chi_{(3)}^{2}=121.83, p=3.1 \mathrm{e}-26$, Kruskal-Wallis test. $\boldsymbol{D}$, Action initiation and response inhibition were measured by the number of premature responses scored when mice directly entered the side choice port without responding to the initiation cue by poking into the center port. The frequency of premature responses gradually decreased during 10 consecutive testing sessions ( $n=67$ mice, main effect of session, $\chi_{(9)}^{2}=$ $102.04, p=6.1 \mathrm{e}-18$, Friedman test). or failure in trial initiation by counting the number of premature responses as a behavioral measure of impulsivity (Chudasama et al., 2003; Kobayashi et al., 2013) (Fig. 1D). Photoinhibition of the $\mathrm{mPFC}$ during the pre-start period significantly increased the frequency of premature responses (Fig. $2 B$; WT; $n=11$ mice, median $=0.49$ (Laser OFF); 0.46 (Pre-start), $\mathrm{W}=48, p=0.21$, VGAT; $n=12$ mice, median $=0.36$ (Laser OFF); 0.78 (Pre-start), $\mathrm{W}=77, p=0.00098$, Wilcoxon signed-rank test), whereas inactivation of the mPFC during the post-choice period had no effect on the frequency of premature responses in the subsequent trial (Fig. $2 D)$ : WT, $n=11$ mice, median $=0.48$ (Laser OFF); 0.51 (Post-choice), $\mathrm{W}=34, p=0.97, \mathrm{VGAT} ; n=12$ mice, median $=$ 0.44 (Laser OFF); 0.37 (Post-choice), $\mathrm{W}=17, p=0.092$, Wilcoxon signed-rank test. This result indicated that the mPFC was directly involved in impulse control.

To determine whether photoinhibition of the mPFC could also alter behavioral flexibility, we next measured the choice bias that each animal displayed for the right or left nose poke. We calculated the choice bias index for each animal as the difference between left choice probability and right choice probability (Fig. $2 C$, top left bar graph). Photoinhibition during the initiation period (pre-start) and during the choice period (pre-choice) significantly induced a bias in choice (Fig. 2C): WT, $n=11$ mice, median $=0.072$ (Laser OFF); 0.073 (Pre-choice), $\mathrm{W}=37, p=$ 0.76 , VGAT; $n=12$ mice, median $=0.066$ (Laser OFF); 0.20 (Pre-choice), $\mathrm{W}=75, p=0.0024$, Wilcoxon signed-rank test, whereas inactivation during the post-choice period did not affect choice bias in the subsequent trial (Fig. $2 E$ ): WT, $n=11$ mice, median $=0.069$ (Laser OFF); 0.096 (Post-choice), $\mathrm{W}=46, p=$ 0.28 , VGAT; $n=12$ mice, median $=0.066$ (Laser OFF); 0.076 (Post-choice), $\mathrm{W}=41, p=0.91$, Wilcoxon signed-rank test. Control WT mice subjected to identical surgeries, stimulation parameters, and training routines did not show premature responses or choice bias at any of the time periods (Fig. $2 B-E$ ).

We next investigated the effect of mPFC inactivation in more detail. First, we analyzed trials with different outcome history. We calculated the choice bias indices and found that mPFC silencing induced a significant increase in choice bias only when unrewarded trials were included in the past two trials (Fig. $3 A$ ): VGAT, $n=12$ mice (Trial $(n-2)(n-1))=($ Rewarded, Rewarded); median $=0.15$ (Laser OFF); 0.29 (Pre-choice), $\mathrm{W}=$ $49, p=1.00$ (Trial $(n-2)(n-1))=($ Unrewarded, Rewarded $)$; median $=0.11$ (Laser OFF); 0.13 (Pre-choice), $\mathrm{W}=70, p=$ 0.048 (Trial $(n-2)(n-1))=($ Rewarded, Unrewarded); median $=0.15$ (Laser OFF); 0.29 (Pre-choice), $\mathrm{W}=70, p=0.048$ $($ Trial $(n-2)(n-1))=($ Unrewarded, Unrewarded $) ;$ median $=$ 0.12 (Laser OFF); 0.31 (Pre-choice), $\mathrm{W}=71, p=0.037$, Wilcoxon signed-rank test for Laser OFF versus Pre-choice). $p$ values were multiplied by 4 for Bonferroni's correction of $p$ values. These results indicate that animals have different level of behavioral flexibility depending on the recent outcome history. Next, we used a logistic regression model to predict animals' choices in upcoming trials from the animals' recent trial history. We observed the dependence of upcoming choice on past outcomes as the deviation of regression coefficients from 0 (Fig. $3 B$ ): $n=12$ mice, $\mathrm{W}($ Rew -5 , Rew -4 , Rew -3 , Rew -2 , Rew -1 , Unrew -5 , Unrew -4 Unrew -3 , Unrew -2 , Unrew -1$)=2,7,3,0,0,13$, $32,39,16,0, p$ value $($ Rew -5 , Rew -4 , Rew -3 , Rew -2 , Rew -1 , Unrew -5 , Unrew -4 Unrew -3 , Unrew -2 , Unrew -1$)=0.015$, $0.093,0.024,0.0049,0.0049,0.42,1.00,1.00,0.77,0.0049$ (onesample signed rank test). The logistic regression model reveals that the effect of silencing is observed in bias terms and not in regression coefficient for choices (Fig. $3 B): n=12$ mice, $\mathrm{W}($ Rew -5 , Rew -4 , 


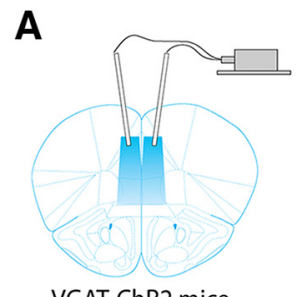

VGAT-ChR2 mice

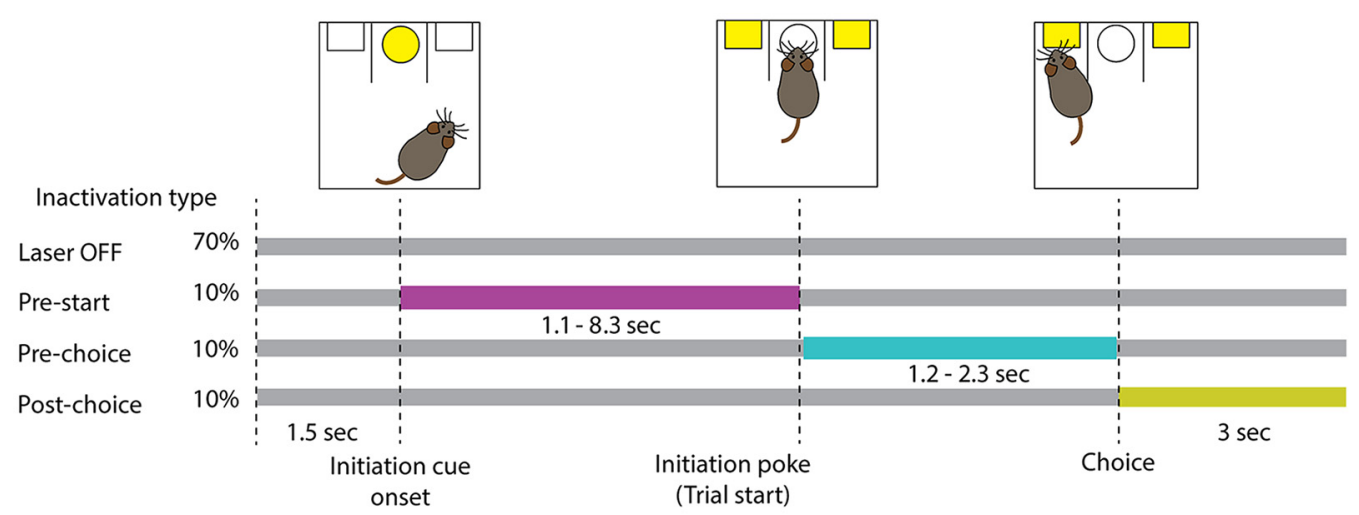

B

\section{Premature response}
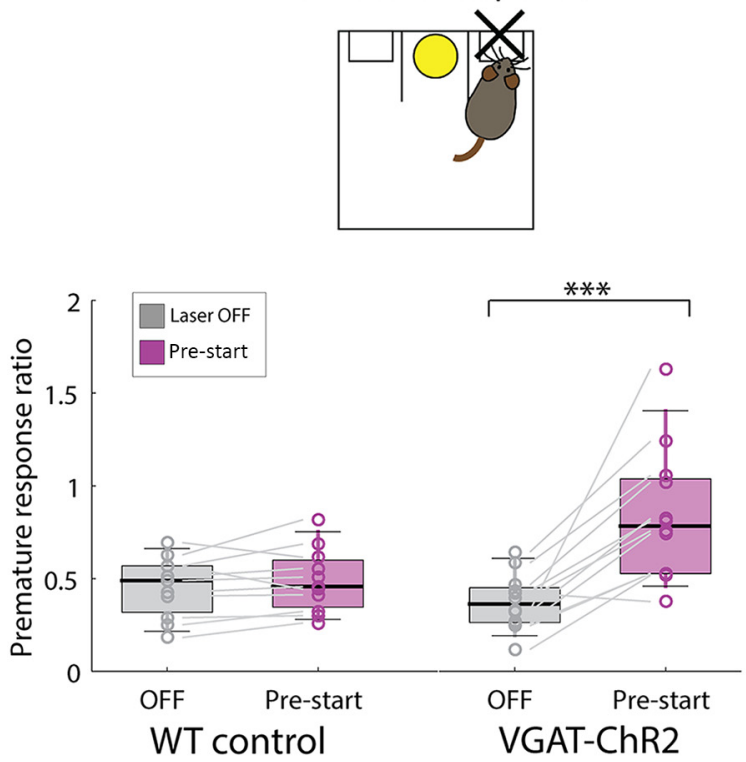

D

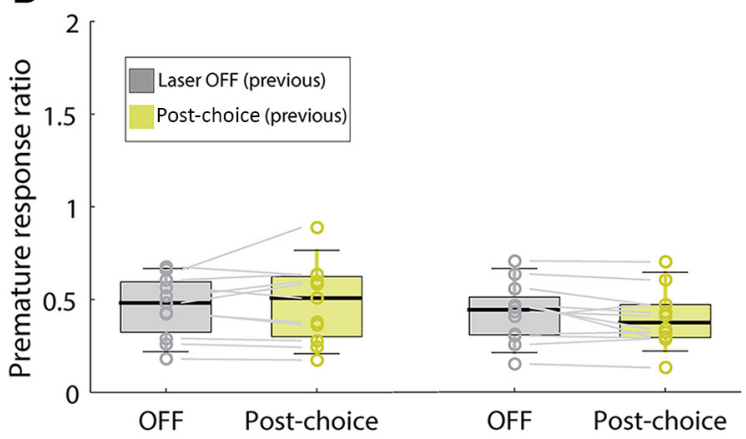

(Previous trial) (Previous trial) (Previous trial) (Previous trial)

WT control

VGAT-ChR2
C

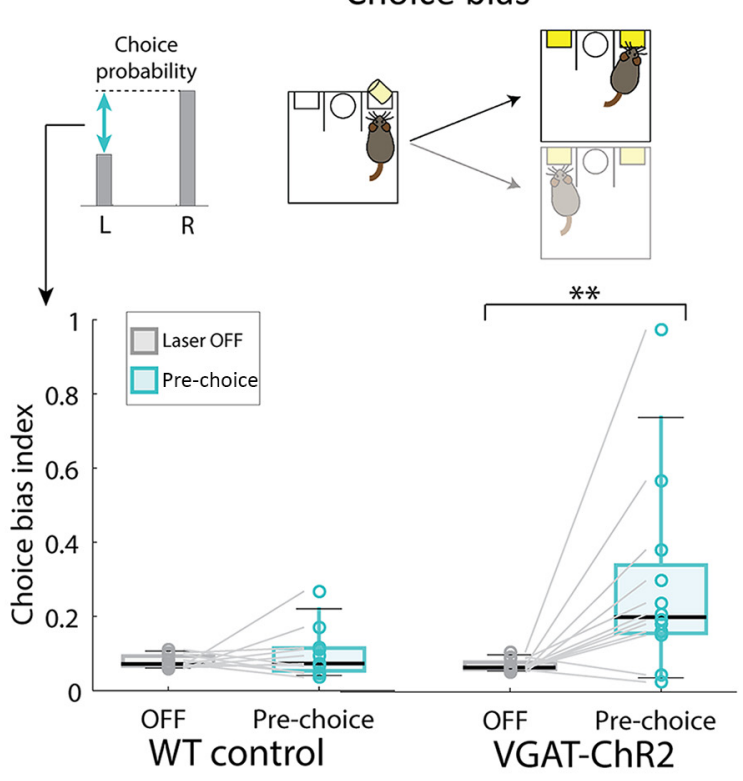

E

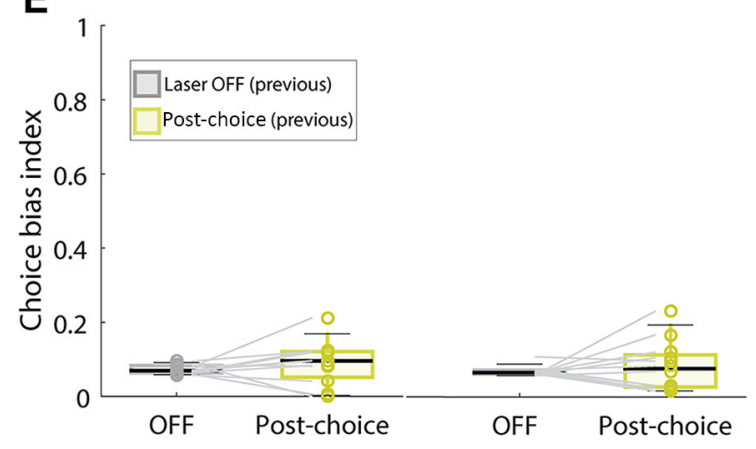

(Previous trial) (Previous trial) (Previous trial) (Previous trial)

VGAT-ChR2

Figure 2. Interneuron-mediated mPFC inactivation impairs impulse control and behavioral flexibility. $\boldsymbol{A}$, Left, Scheme of the bilateral placement of fiberoptics in the mPFC of VGAT-ChR2 mice for optogenetic activation of cortical interneurons and consequent suppression of pyramidal neuron activity. Right, Time periods of optogenetic stimulation during the probabilistic reversal task. Blue light laser ( $5 \mathrm{~ms}$ pulse at $40 \mathrm{~Hz}$ ) was delivered in $10 \%$ of the trials in one session at three different times during the task: (1) laser during the pre-start period (magenta, 1.1, 3.2 , and $8.3 \mathrm{~s}$ for 25,50 , and 75 percentile) was turned on between the onset of the center LED light and the center port poke; (2) laser during the pre-choice period (cyan, 1.2, 1.6, and 2.3 s for 25,50 , and 75 percentile) was turned on between the center port poke and the side port poke; and (3) laser during the post-choice period of the previous trial (yellow) was kept on for $3 s$ after choice. $B$, Photoinhibition of pyramidal neurons during the pre-start period induced a significant increase in the frequency of premature responses (WT, $n=11$ mice, $p>0.05 ;$ VGAT-ChR2, $n=12$ mice). ${ }^{* *} p<0.001$ (Wilcoxon signed-rank test). C, Behavioral flexibility was quantified by the choice bias index (difference between left and right choice probability for each mice). Photoinhibition of pyramidal neurons during the pre-choice period induced a significant increase in choice bias in VGAT-ChR2 mice (WT, $n=11$ mice, $p>0.05 ;$ VGAT-ChR2, $n=12$ mice). ${ }^{* *} p<0.01$ (Wilcoxon signed-rank). $\boldsymbol{D}, \boldsymbol{E}$, Photoinhibition of pyramidal neurons during the post-choice period did not affect either premature responses or choice bias in the following trials $(\boldsymbol{D}, \boldsymbol{E})$ : WT, $n=11$ mice, $p>0.05 ; \mathrm{VGAT-ChR2,}$ $n=12$ mice, $p>0.05$ (Wilcoxon signed-rank test). For the position of fiber placements and estimate of the area receiving photoinhibition, see Figure $2-1$ (available at https://doi.org/10.1523/JNEUROSCI.3537-17.2018.f2-1). 


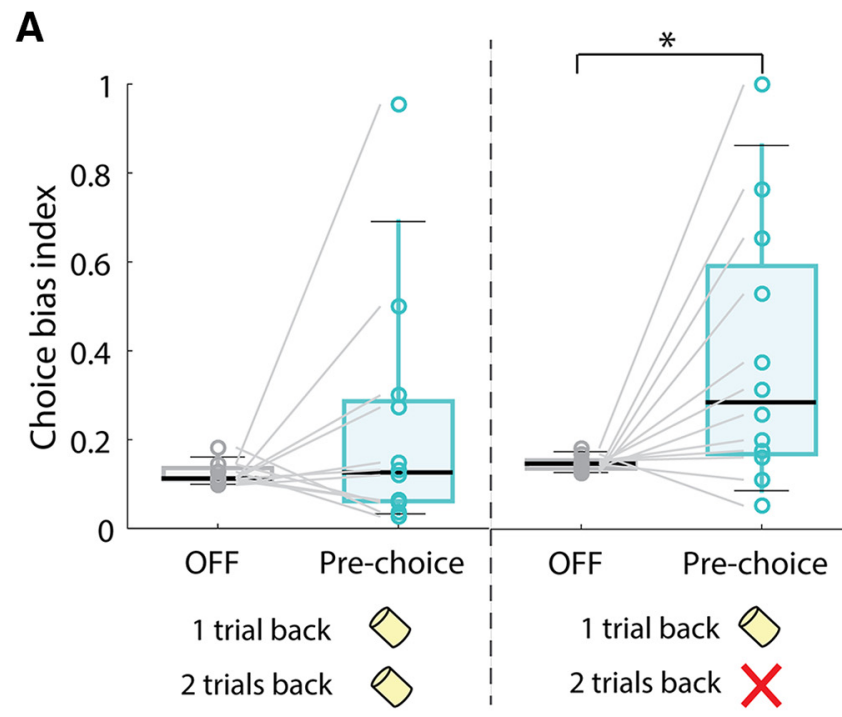

B

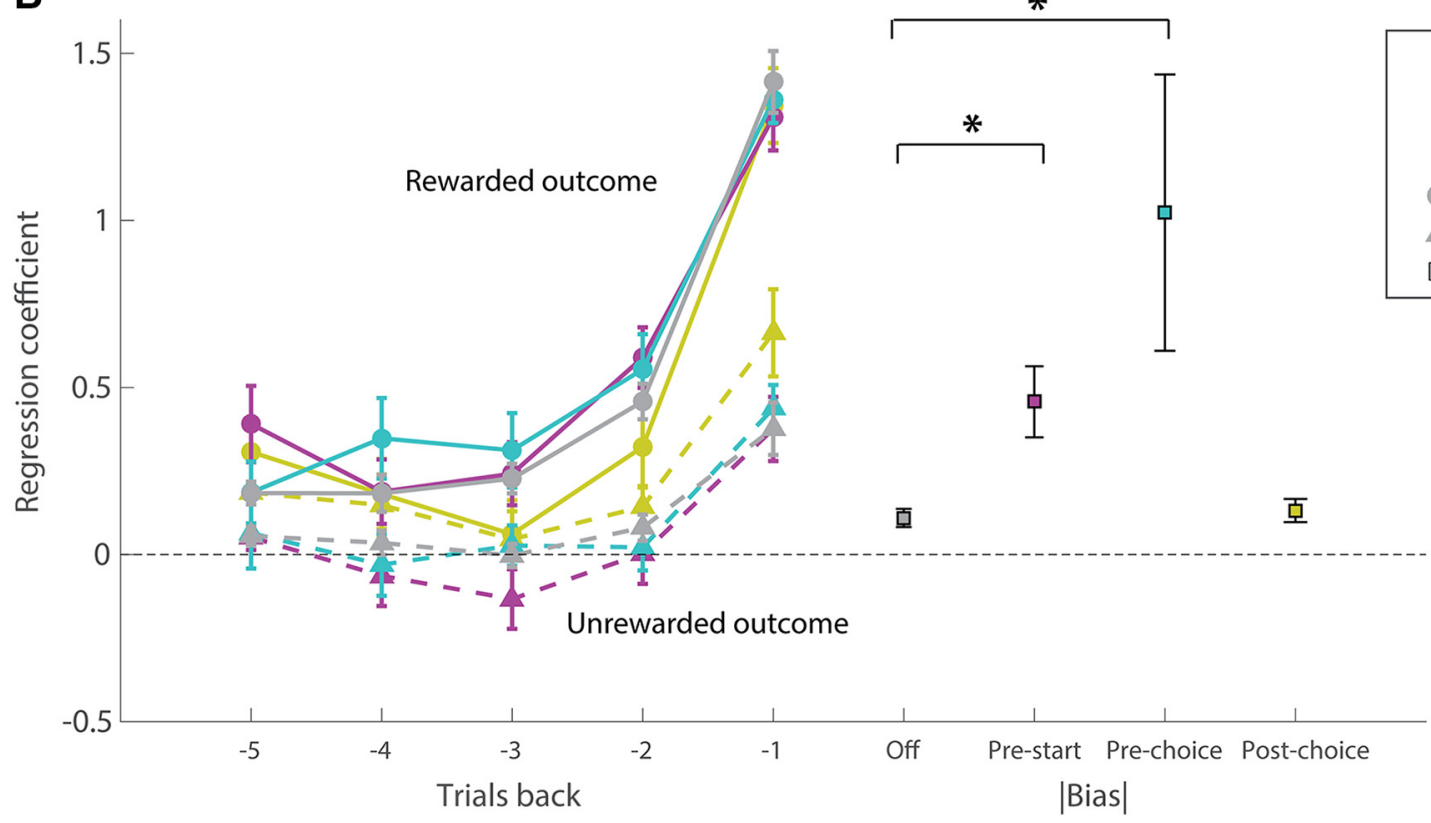

Figure 3. Effect of mPFC on choice bias depends on outcome history, but mPFC inactivation does not affect the evaluation of outcomes. $A$, Choice bias indices calculated separately for different past outcomes. Choice bias indices in pre-choice inactivation trials were significantly larger than corresponding choice bias indices for laser off trials if unrewarded trials occurred during the past two trials but not if the two past trials were both rewarded (left). VGAT-ChR2, $n=12$ mice, Trial $(n-2)(n-1)=$ (Rewarded, Rewarded); median $=0.15$ (Laser 0FF); 0.29 (Pre-choice), W $=49, p=$ $1.00($ Trial $(n-2)(n-1))=($ Unrewarded, Rewarded); median $=0.11$ (Laser OFF); 0.13 (Pre-choice), W $=70, p=0.048($ Trial $(n-2)(n-1))=($ Rewarded, Unrewarded); median $=0.15$ (Laser OFF); 0.29 (Pre-choice), $\mathrm{W}=70, p=0.048$ (Trial $(n-2)(n-1))=$ (Unrewarded, Unrewarded); median $=0.12$ (Laser OFF); 0.31 (Pre-choice), W= 71, $p=0.037$, Wilcoxon signed-rank test for Laser Off versus Pre-choice. $p$ values were multiplied by 4 for Bonferroni's correction of $p$ values. $\boldsymbol{B}$, Choice was modeled using a logistic regression model with independent variables for outcomes and inactivation types. Regression coefficients for rewarded or unrewarded outcomes were unchanged in pre-start (magenta) and pre-choice inactivation (cyan) compared with corresponding coefficients in laser-off (gray) trials. This indicated that the increased choice bias (squares) induced by pre-start or pre-choice photoinhibition was independent from the processing of reward information. For inactivation conditions, coefficients of choice plus those of choice $\times$ laser interaction were plotted $(a+c, a+e, a+g, b+d, b+f, b+h$; for the labeling of variables, see Materials and Methods). Absolute values of coefficients of bias terms were significantly increased in pre-start and pre-choice inactivation (VGAT-ChR2, $n=12$ mice, $0 \mathrm{FF}$ vs Pre-start, $0 \mathrm{FF}$ vs Pre-choice). ${ }^{*} p<0.05$ (Wilcoxon signed-rank test with Bonferroni's correction of $p$ value).

Rew -3 , Rew -2 , Rew -1 , Unrew -5 , Unrew -4 , Unrew -3 , Unrew -2 , Unrew -1 , $\mid$ bias $\mid)=63,40,39,64,33,35,30,25,29,40$, 75 (Laser OFF vs Pre-start), 41, 54, 50, 44, 32, 36, 19, 39, 23, 49, 76 (Laser OFF vs Pre-choice), 52, 40, 19, 21, 27, 50, 52, 48, 50, 66, 48 (Laser OFF vs Post-choice), -2 , Unrew -1 , | bias $\mid$ ) = 0.70, 1.00, 1.00, $0.57,1.00,1.00,1.00,1.00,1.00,1.00,0.027$ (Laser OFF vs Pre-start), $1.00,1.00,1.00,1.00,1.00,1.00,1.00,1.00,1.00,1.00,0.016$ (Laser OFF vs Pre-choice), 1.00, 1.00, 1.00, 1.00, 1.00, 1.00, 1.00, 1.00, 1.00, $0.38,1.00$ (Laser OFF vs Post-choice) (Wilcoxon signed rank test). $p$ values were multiplied by 11 (number of coefficients for each inactivation condition) for Bonferroni's correction of $p$ values. These results indicated that the influence of $\mathrm{mPFC}$ on flexible choice behaviors depends on the trial history, but that evaluation of the behavioral outcomes was not affected by mPFC silencing.

Although choice bias and premature responses are distinct behavioral readouts, it is possible that these could be induced by common cognitive or motor deficits. To assess this possibility, we compared the direction of choice bias and the direction of pre- 


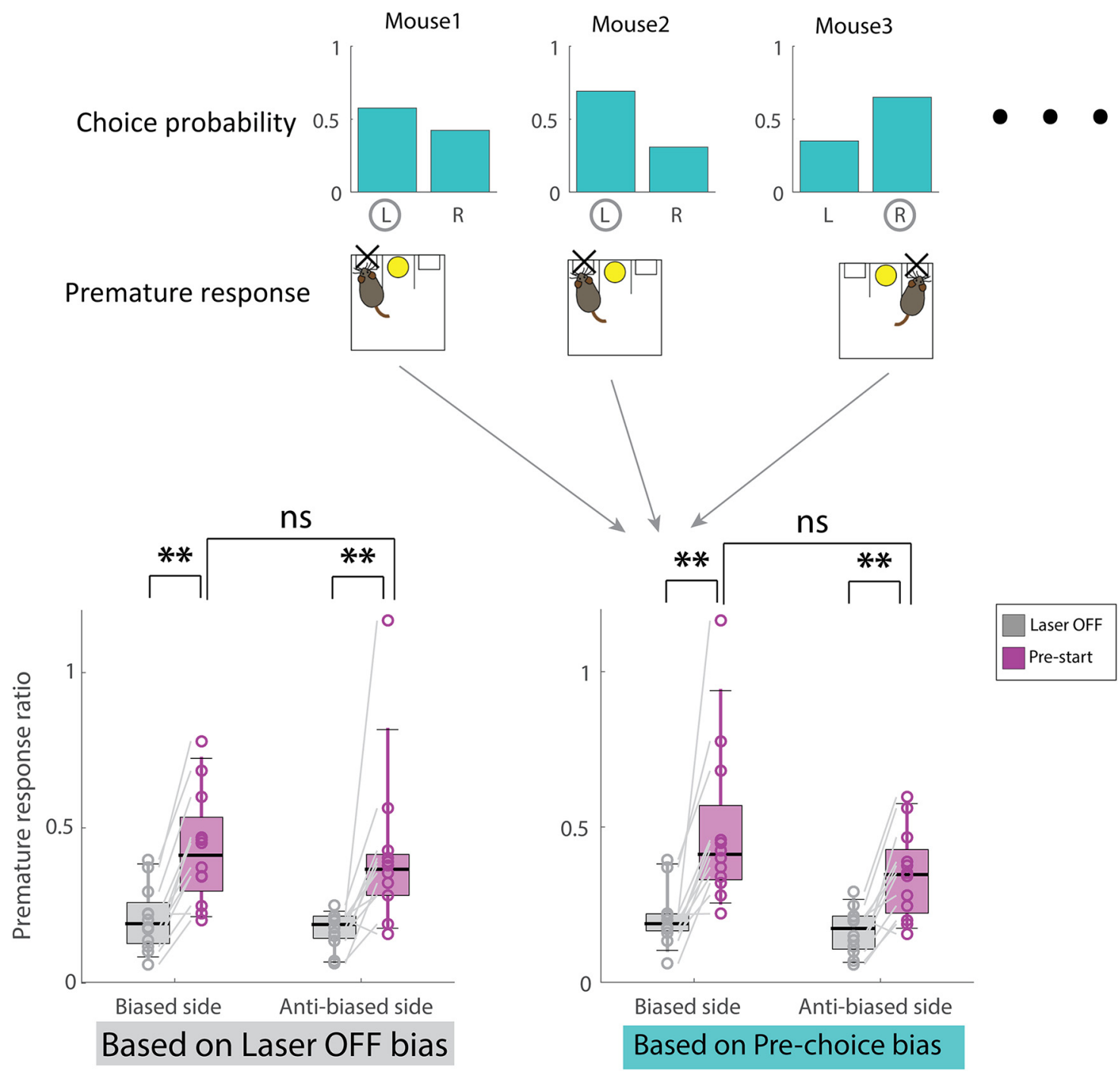

Figure 4. Interneuron-mediated mPFC photoinhibition induces premature responses and choice bias through different cognitive or motor deficits. mPFC photoinhibition during the initiation cue (pre-start: magenta bars) increased premature responses for both biased and anti-biased sides. The biased side corresponds to the side with higher choice probability in each inactivation condition. For all inactivation conditions, VGAT-ChR2: $n=12$ mice. ${ }^{* *} p<0.01$, Laser OFF versus Pre-start inactivation (Wilcoxon signed-rank test). ns: $p>0.05$ for bias versus nonbiased direction of pre-start trials (Wilcoxon signed-rank test). All $p$ values were corrected with Bonferroni's method.

mature responses. This analysis showed that $\mathrm{mPFC}$ photoinhibition increased the frequency of premature responses to either of the two choice ports regardless of the direction of choice bias in the same animals (Fig. 4): $n=12$ mice, Left (bias direction in Laser OFF trials), median $=0.19$ (Laser OFF, biased side); 0.41 (Pre-start, biased side); 0.19 (Laser OFF, anti-biased side); 0.36 (Pre-start, anti-biased side), $\mathrm{W}=78$ (biased side, Laser OFF vs Pre-start); 77(anti-biased side, Laser OFF vs Pre-start); 25 (Prestart, biased side vs anti-biased side), $p$ values $=p=0.0015$ (biased side, Laser OFF vs Pre-start); 0.0029 (anti-biased side, Laser OFF vs Pre-start); 0.90 (Pre-start, biased side vs anti-biased side), Right (bias direction in Pre-choice trials), median $=0.19$ (Laser OFF, biased side); 0.41 (Pre-start, biased side); 0.17 (Laser OFF, anti-biased side); 0.35 (Pre-start, anti-biased side), $\mathrm{W}=78$ (biased side, Laser OFF vs Pre-start); 77(anti-biased side, Laser OFF vs Pre-start); 11 (Pre-start, biased side vs anti-biased side), $p$ values $=p=0.0015$ (biased side, Laser OFF vs Pre-start); 0.0029 (anti-biased side, Laser OFF vs Pre-start); 0.081 (Pre-start, biased side vs anti-biased side)). This observation indicates that choice bias and premature responses are dissociable behavioral read- outs, and supports the conclusion that the MPFC may modulate impulsivity and behavioral flexibility through distinct cognitive processes.

\section{Layer-specific pyramidal neurons in the MPFC}

The dissociation of choice bias and premature responses as separate behavioral readouts strongly indicated the involvement of distinct neural circuits in the mPFC. The cerebral cortex is composed of diverse cell types with specific molecular signatures (Gong et al., 2007; Gerfen et al., 2013) that process distinct information even in the same cortical area. To identify the underlying neural circuits that support behavioral flexibility and impulsivity, we conducted cell type-specific optogenetic manipulations of the $\mathrm{mPFC}$ using transgenic mouse lines that target genetically defined cell types. We first characterized Cre-recombinase expressing mouse lines that potentially target different population of pyramidal neurons in the mPFC (Fig. 5). Sagittal images of Colgalt2Cre (NF111), Syt6-Cre (KI 109), and Sepw1-Cre (NP39) mouse lines showed distinct patterns of Cre expression in the cortex (Fig. $5 A, C, E)$. To confirm that Cre-recombinase is expressed in adult 
A

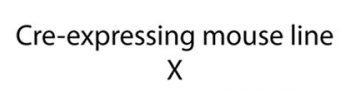

Rosa26-Floxed-EGFP

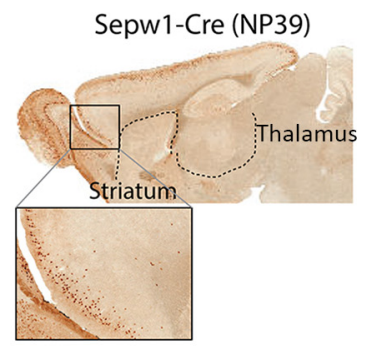

C Colgalt2-Cre (NF111)

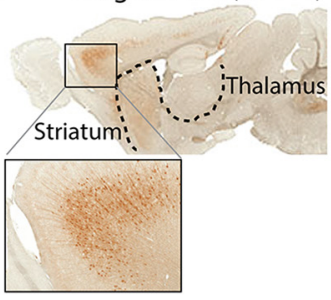

E

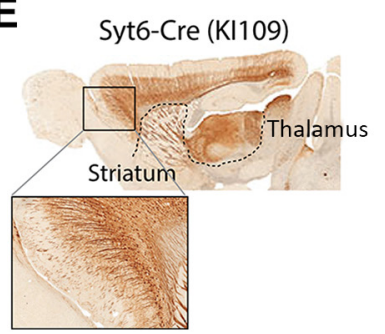

B
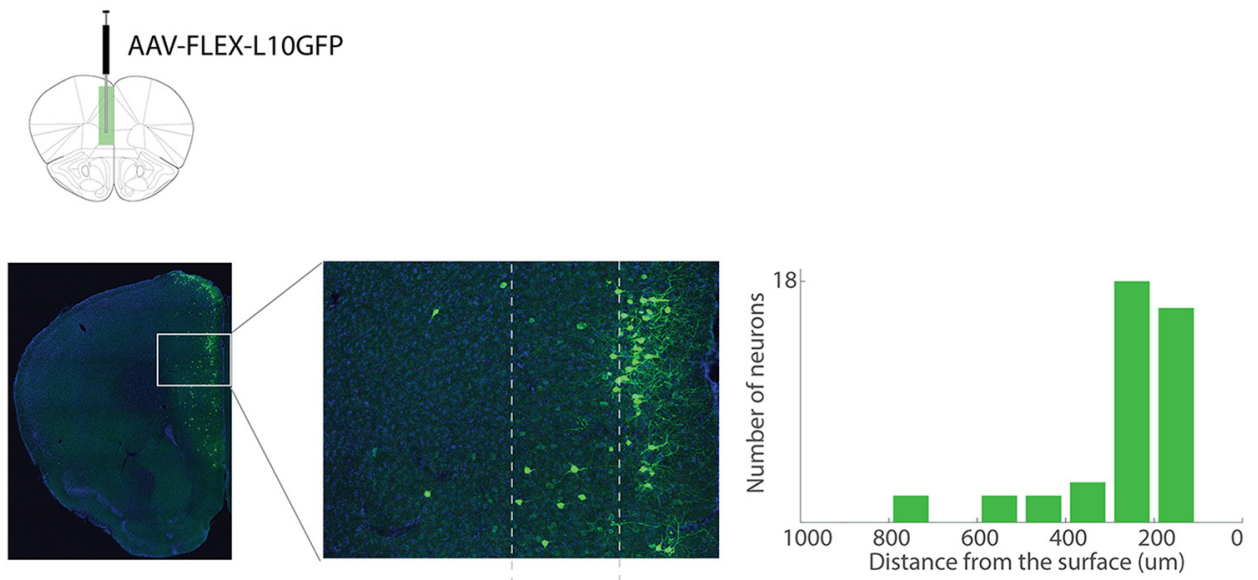

D
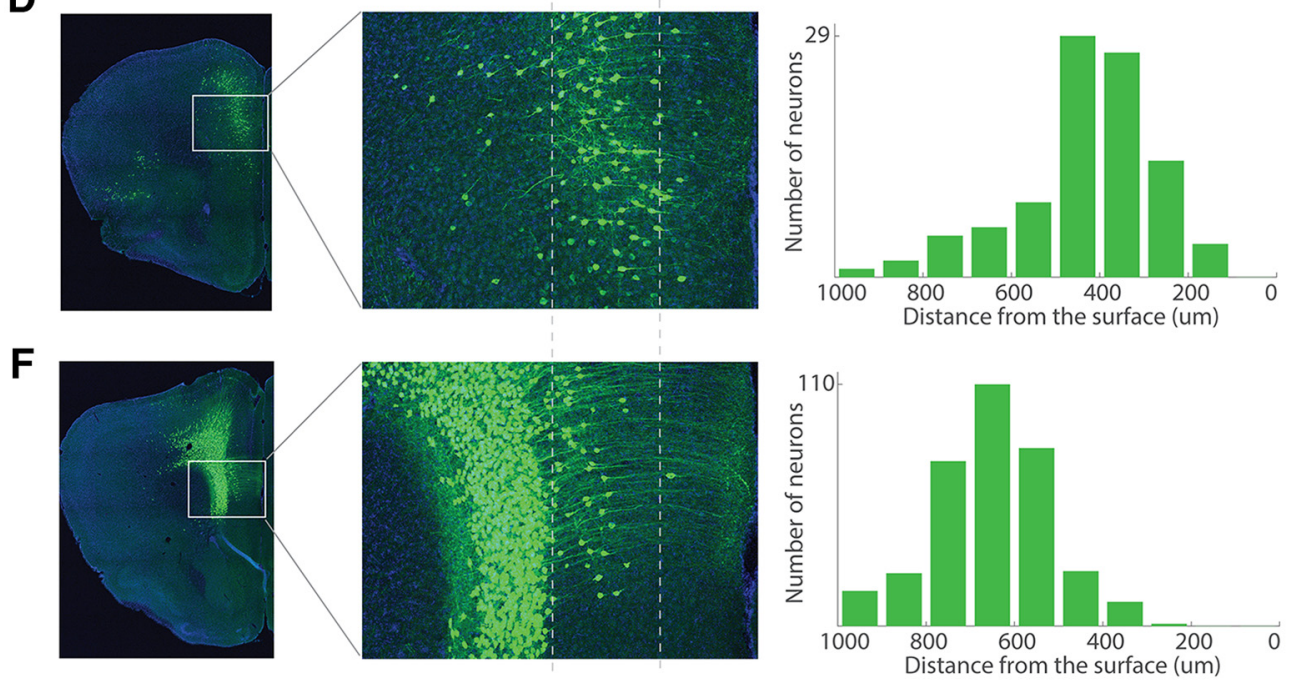

Figure 5. Cre-expressing transgenic mouse lines that target pyramidal neurons in different cortical layers in the mPFC. $A, C, E$, Sagittal sections of Cre-expressing mouse lines crossed with the reporter Rosa26-floxed-EGFP reporter line. A, Sepw1-Cre (NP39), (C) Colgalt2-Cre (NF111), and (E) Syt6-Cre (KI109). B, D, F, Left, Location of Cre-positive neurons in the mPFC of each mouse line was visualized by unilateral injection of AAV-FLEX-L10-EGFP virus in Sepw1-Cre (B), Colgalt2-Cre (D), and Syt6-Cre ( $\boldsymbol{F}$ ). Middle column, Magnified views of images in the left column. Right column, Number of cells along cortical depth in the areas shown in the middle column.

mice and to determine the localization of cre-positive neurons in the mPFC, we injected cre-dependent adeno-associated virus (AAV) expressing the ribosomal L10-GFP fusion protein (Nectow et al., 2017) (Fig. $5 B, D, F$ ). The location of the cell bodies visualized by L10-GFP showed that each Cre mouse line mostly labeled neurons in distinct layers in the mPFC (Fig. 5B,D,F, middle and right panels): Sepw1Cre (NP39) labeled layer 2/3 pyramidal neurons; Colgalt2-Cre (NF111) labeled layer 5 neurons; and Syt6-Cre (KI 109) labeled layer 6 neurons in the mPFC.

We next traced the axonal projections after unilateral injection of AAV-Flex-ArchT in the mPFC of these different cortical mouse lines (Fig. 6). Cre-positive neurons in the mPFC of Colgalt2-Cre (NF111) mice projected strongly to the striatum with many fewer projections to other subcortical structures such as the basolateral amygdala and zona incerta (Fig. 6A). Crepositive neurons in Syt6-Cre (KI109) mice showed axon terminals exclusively in the thalamus along with labeling of axon bundles passing through the striatum (Fig. 6B). The axons were localized predominantly in mediodorsal, parafascicular, and ventromedial thalamic nuclei. Cre-positive neurons in Sepw1-Cre (NP39) mice projected to the contralateral cortical hemisphere in the same areas of the PFC, as well as distinct cortical areas in the ipsilateral hemisphere (Fig. 6C). Together, these analyses indicated that the Colgalt2-Cre (NF111) mouse line specifically targets corticostriatal projections from the mPFC, the Syt6-Cre line is specific for corticothalamic projections and the Sepw1-Cre labels corticortical projections.

\section{Corticostriatal neurons influence choice bias without affecting impulsivity}

Corticostriatal projection neurons located in layer 5 of the mPFC constitute a cell population that is involved in decision-making, and they may be affected in neuropsychiatric disorders, such as OCD (Burguière et al., 2015). To investigate the contribution of this cell type to flexible choice behavior, we used transgenic Colgalt2-Cre (NF111) mice for bilateral injections of the Credependent AAV expressing ArchT for photoinhibition experiments. We simultaneously implanted bilateral optical fibers in the mPFC of Colgalt2-Cre mice (Fig. 7A; Fig. 7-1 A, available at https://doi.org/10.1523/JNEUROSCI.3537-17.2018.f7-1). Photoinhibition experiments were performed using continuous green light $(\lambda=532 \mathrm{~nm})$ delivered at $10 \mathrm{~mW}$ laser power according to prior studies (Bukalo et al., 2015; Bolkan et al., 2017), which showed that these conditions are sufficient to inhibit the activity of pyramidal 
A

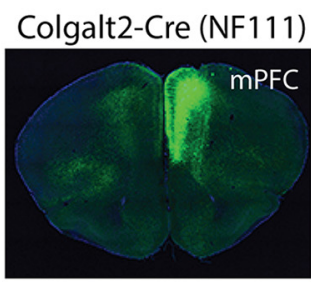

Injection site
Projection targets

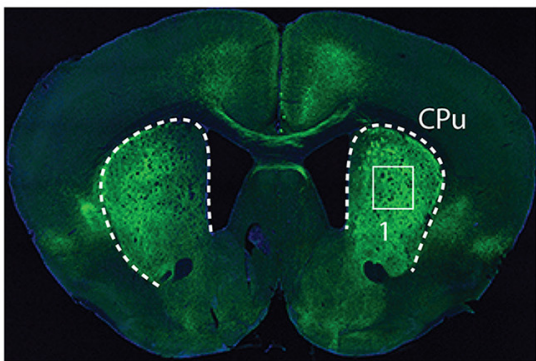

AP: 1.18

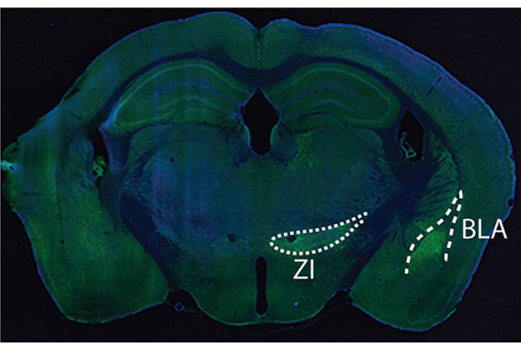

AP: -1.70

Inset 1

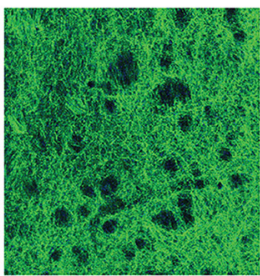

|B

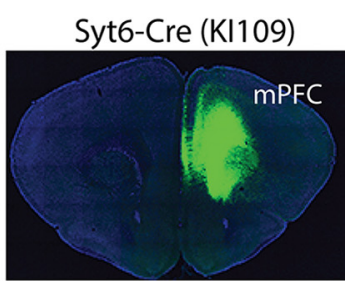

C

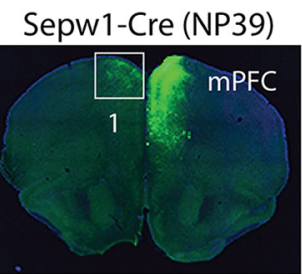

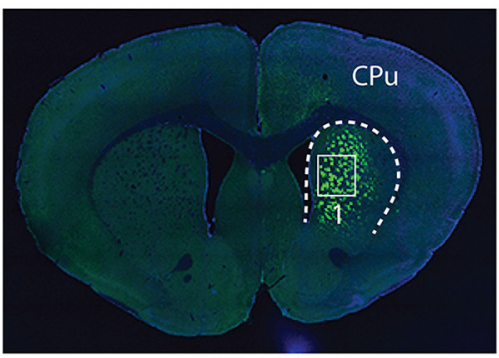

AP: 1.18

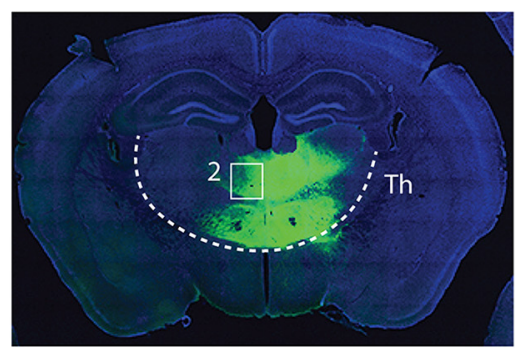

AP: -1.70

Inset 1

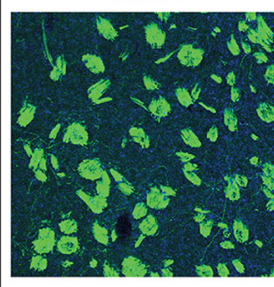

Inset 2

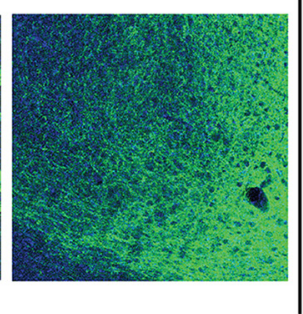

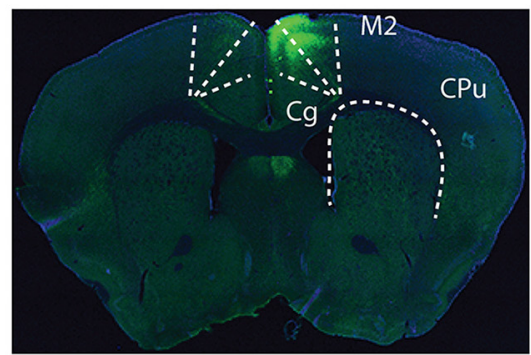

AP: 1.18

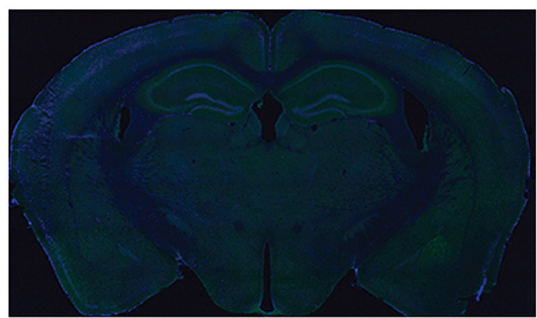

AP: -1.70

Inset 1

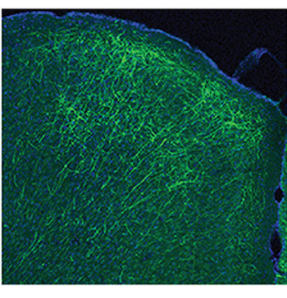

Figure 6. Axonal projections of mPFC cortical pyramidal cells. $A$, Tracing axonal projections by unilateral injection of AAV-FLEX-ArchT in the mPFC of Colgalt2-Cre (NF111) mice showed dense projections of Cre-positive neurons in the striatum (Inset 1). B, Tracing of AAV-FLEX-ArchT-labeled projections in Syt6-Cre (KI109) mice showed corticothalamic axon bundles in the striatum (Inset 1) and axon terminals in the thalamus (Inset 2), including mediodorsal, ventromedial, and parafascicular nuclei. C, Tracing of AAV-FLEX-ArchT-labeled projections in the mPFC of Sepw1-Cre (NP39) mice showed mostly ipsilateral and contralateral cortical projections (Inset 1): anteroposterior $1.18 \mathrm{~mm}$ and anteroposterior -1.70 mm. BLA, Basolateral amygdala; Cg, Cingulate cortex; CPu, caudate-putamen; Th, thalamus; M1, primary motor cortex; M2, secondary motor cortex; ZI, zona inserta.

neurons in the $\mathrm{mPFC}$ and induce behavioral phenotypes. Photoinhibition of Colgalt2-Cre neurons in layer 5 of the mPFC at different time periods in the probabilistic reversal task showed that premature responses were not affected by pre-start inactivation (Fig. 7B): GFP; $n=8$ mice, median $=0.47$ (Laser OFF); 0.55 (Pre-start), $\mathrm{W}=29$, $p=0.15$, Colgalt2-ArchT; $n=10$ mice, median $=0.35$ (Laser OFF); 0.38 (Pre-start), $\mathrm{W}=32, p=0.7$, Wilcoxon signed-rank test. In contrast, photoinhibition induced choice bias to either the left or the right direction as we observed in VGAT-ChR2 mice (Fig. 7C): GFP; $n=8$ mice, median $=0.064$ (Laser OFF); 0.058 (Pre-choice), $\mathrm{W}=$ $18, p=1.00$, Colgalt2-ArchT; $n=10$ mice, median $=0.084$ (Laser OFF); 0.19 (Pre-choice), $\mathrm{W}=55, p=0.0020$, Wilcoxon signed-rank test. These results demonstrate that, among the behavioral effects induced by whole mPFC inactivation, only choice bias was altered by silencing the layer $5 \mathrm{mPFC}$ neurons targeted in Colgalt2-Cre mice.
Although the striatum is the major projection target of Creexpressing neurons in Colgalt2-Cre (NF111) mice, these neurons also project to other structures (Fig. 6A). To ensure that the observed behavioral changes resulted from specific inactivation of corticostriatal projections, we performed photoinhibition of axon terminals in the striatum (Fig. $7 D$; Fig. $7-1 B$, available at https://doi.org/10.1523/JNEUROSCI.3537-17.2018.f7-1). Illumination of ArchT axon terminals in the striatum also induced choice bias (Fig. $7 F$ ): Colgalt2-ArchT axon terminal; $n=9$ mice, median $=0.071$ (Laser OFF); 0.17 (Pre-choice), $\mathrm{W}=44, p=$ 0.0078 , Wilcoxon signed-rank test, with no impact on premature responses (Fig. $7 E$ ): Colgalt2-ArchT axon terminal; $n=9$ mice, median $=0.49$ (Laser OFF); 0.54 (Pre-start), $\mathrm{W}=37, p=0.098$, Wilcoxon signed-rank test, demonstrating that mPFC corticostriatal projection neurons regulate behavioral flexibility. 


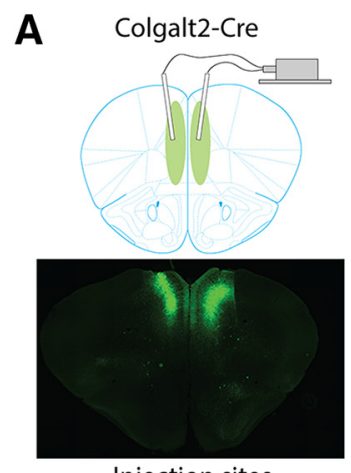

Injection sites
B

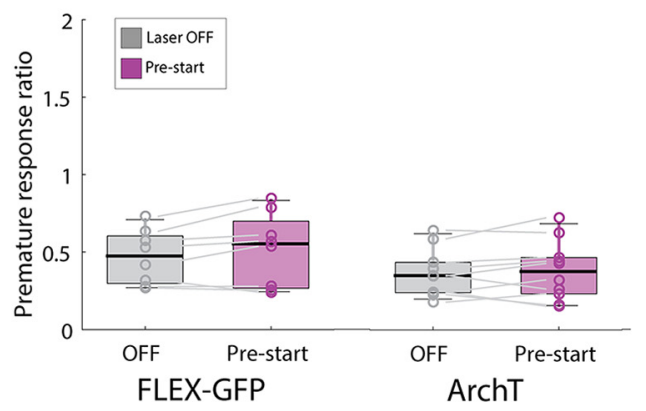

C

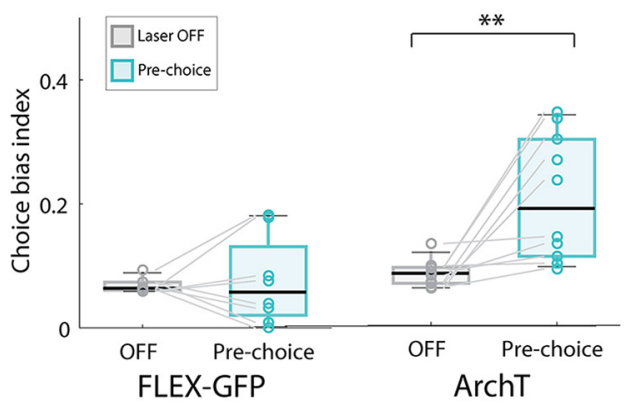

D
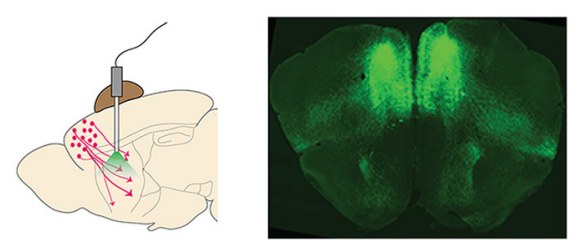

Injection sites
E

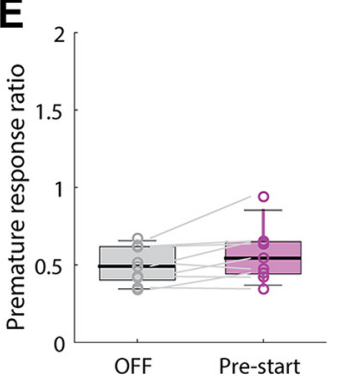

ArchT axon terminal
$\mathbf{F}$

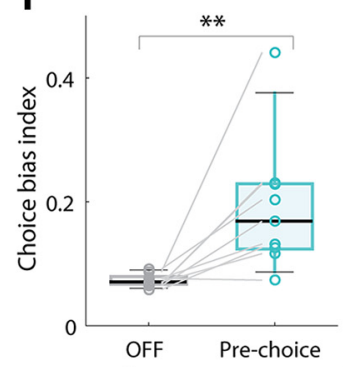

ArchT axon terminal
G

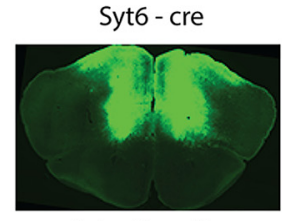

Injection site

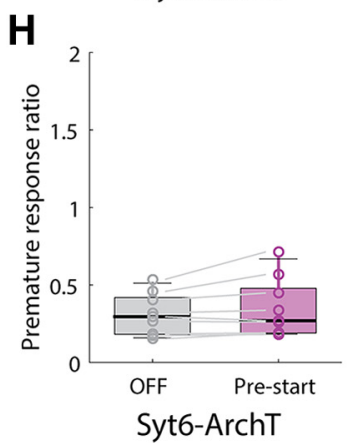

I

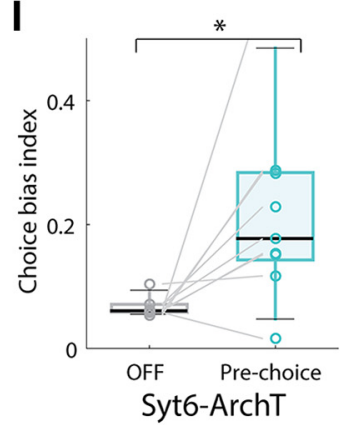

J

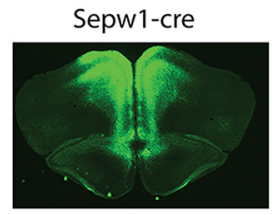

Injection site

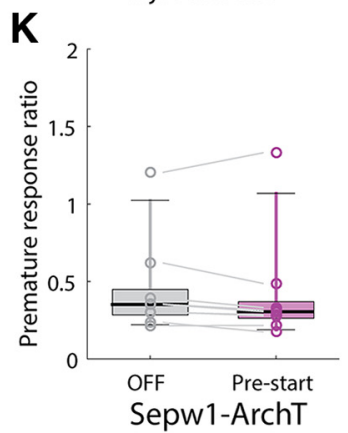

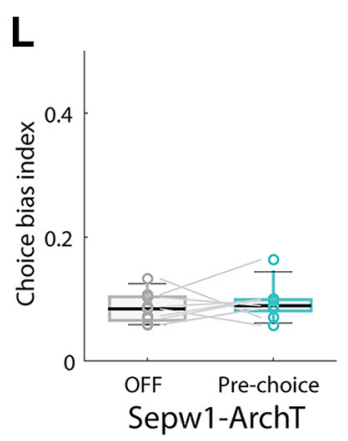

Figure 7. Photoinhibition of $\mathrm{mPFC}$ corticostriatal and corticothalamic neurons impaired behavioral flexibility without affecting impulsivity. A, AAV-FLEX-ArchT bilateral injection and optical fiber placement in the mPFC of Colgalt2-Cre mice. B, Premature responses were not affected by photoinhibition in ArchT expressing Colgalt2-Cre mice (GFP: $n=8$ mice, $p>0.05$, ArchT: $n=10$ mice, $p>0.05$, Wilcoxon signed-rank test). C, Inactivation during the pre-choice period induced a significant increase in choice bias index (GFP: $n=8, p>0.05$, ArchT: $n=10$ mice, 0 FF vs Pre-choice). ${ }^{* *} p<0.01$ (Wilcoxon signed-rank test). $\boldsymbol{D}$, Diagram depicting the optical stimulation of axon terminals in the dorsal striatum of Colgalt2-Cre mice expressing AAV-FLEX-ArchT in the mPFC. $\boldsymbol{E}$, Premature responses were not affected by photoinhibition (ArchT axon terminals: $n=9$ mice, $p>0.05$, Wilcoxon signed-rank test). $\boldsymbol{F}$, Photoinhibition at axon terminals in the striatum during the pre-choice period induced a significant increase in choice bias index (ArchT axon terminals: $n=9$ mice, OFF vs Pre-choice). ${ }^{* *} p<0.01$ (Wilcoxon signed-rank test). G, Location of AAV-FLEX-ArchT virus injection and optical fiber implants in the mPFC of Syt6-Cre mice. $\boldsymbol{H}$, Premature responses were not affected by photoinhibition of ArchT-positive neurons in Syt6-Cre mice (Syt6-Cre: $n=9$ mice, $p>0.05$, Wilcoxon signed-rank test). I, Photoinhibition of ArchT-positive neurons in Syt6-Cre mice during pre-choice period induced a significant increase in choice bias index (Syt6-Cre: $n=9$ mice, OFF vs Pre-choice). ${ }^{*} p<0.05$ (Wilcoxon signed-rank test). $\boldsymbol{J}$, Location of virus injection and fiber implants in the mPFC of Sepw1-Cre mice. $\boldsymbol{K}$, Premature responses were not affected by photoinhibition of ArchT-positive neurons in Sepw1-Cre mice (Sepw1-Cre: $n=9$ mice, $p>0.05$, Wilcoxon signed-rank test). $L$, Choice bias index was not affected by photoinhibition of ArchT-positive neurons in Sepw1-Cre mice (Sepw1-Cre: $n=9$ mice, $p>0.05$, Wilcoxon signed-rank test). For the virus expression and optical fiber placements, see Figure 7-1 (available at https://doi.org/10.1523/JNEUROSCI.3537-17.2018.f7-1).

Choice bias is also induced by inactivation of layer 6 corticothalamic neurons in the $\mathrm{mPFC}$

Although strong support for the cortico-striato-thalamocortical circuit model of OCD has been obtained in humans and experimental animals (Ting and Feng, 2011; Pauls et al., 2014). Recent studies have stressed the primary importance of corticostriatal projections in OCD (Ahmari et al., 2013; Burguière et al., 2013, 2015; Vaghi et al., 2017), deemphasizing a role for the thalamus in this disorder (Maltby et al., 2005; Woolley et al., 2008; Gilbert et al., 2009; Del Casale et al., 2011). Given the strong direct projections between the mPFC and thalamic nuclei, and the complex behaviors evident in the disorder, we were interested in assessing 
independently the contributions of corticothalamic projections to behavioral flexibility and impulsivity. Layer 6 neurons in the mPFC project exclusively to the thalamus, predominantly targeting the mediodorsal, parafascicular, and ventromedial thalamic nuclei (Fig. 6). To investigate the contribution of this cell type to flexible choice behavior, we used transgenic Syt6-Cre (KI109) mice for bilateral injections of AAV-FLEX-ArchT and bilateral optical fiber placement (Fig. 7G; Fig. 7-1C, available at https:// doi.org/10.1523/JNEUROSCI.3537-17.2018.f7-1). Photoinhibition of this cell type resulted in similar deficits in choice bias as those observed in corticostriatal neurons, whereas the frequency of premature responses was unaffected (Fig. 7 H,I): Syt6-ArchT; $n=9$ mice, Premature response; median $=0.29$ (Laser OFF); 0.27 (Pre-start), $\mathrm{W}=39, p=0.055$, Choice bias; median $=0.06$ (Laser OFF); 0.18 (Pre-choice), $\mathrm{W}=43, p=0.012$, Wilcoxon signed-rank test. Together, our data demonstrate that direct projections from the mPFC to both the striatum and thalamus are important for flexible decision making in mice.

\section{Silencing of layer $2 / 3$ corticocortical neurons in the mPFC does not alter impulsivity or behavioral flexibility in the probabilistic reversal task}

Thus far, we have demonstrated that local interneuron-mediated inactivation of the mouse mPFC alters both impulsivity and behavioral flexibility, whereas cell type-specific photoinhibition of deep layer pyramidal neurons projecting to either the dorsal striatum or midline thalamic nuclei results in inflexible choice, but not premature responses. Given recent data indicating a role for layer $2 / 3$ neurons of the mPFC in stress-induced depressive behaviors (Shrestha et al., 2015) and in modulation of stress by oxytocin (Li et al., 2016), and the comorbidity of OCD and anxiety-related behaviors in humans (Lochner and Stein, 2010; Goodwin, 2015; Brakoulias et al., 2017), we next tested the role of Sepw1-Cre (NP39) positive layer 2/3 neurons in the probabilistic reversal task in mice injected with AAV-FLEX-ArchT and implanted with optical fibers (Fig. 7J; Fig. 7-1 D, available at https:// doi.org/10.1523/JNEUROSCI.3537-17.2018.f7-1). Photoinhibition of these superficial mPFC corticocortical pyramidal cells had no impact on task performance. Thus, mice bilaterally injected with AAV-Flex-ArchT in the mPFC showed no change in either premature response ratio or choice bias index (Fig. $7 \mathrm{~K}, L$ ): Sepw1-ArchT; $n=9$ mice, Premature response; median $=0.35$ (Laser OFF); 0.31 (Pre-start), $\mathrm{W}=9, p=0.13$, Choice bias; median $=0.084$ (Laser OFF); 0.089 (Pre-choice), $\mathrm{W}=29, p=$ 0.5 , Wilcoxon signed-rank test, during photoinhibition in the pre-start and pre-choice periods, respectively.

\section{Discussion}

Behavioral flexibility and impulse control are two prominent behavioral deficits observed in OCD patients. In human studies, these are assessed by cognitive tasks, including reversal learning and stop-signal task (Chamberlain et al., 2006; Remijnse et al., 2006). In contrast, most rodent studies for OCD-related behaviors have focused primarily on the natural behavior repertoire of rodents (e.g., grooming), rather than more complex assays of behavioral flexibility (Welch et al., 2007; Shmelkov et al., 2010; Ahmari et al., 2013). Here, we have used a probabilistic reversal task to investigate the contribution of mPFC cell types to behavioral flexibility and impulse control. We find that impulsivity and behavioral flexibility, as evidenced by changes in the premature response ratio and choice bias index in the probabilistic reversal task, are dissociable processes that can be distinguished by the temporally specific consequences of local mPFC inactivation. In- terestingly, silencing of either corticostriatal or corticothalamic projection neurons in the $\mathrm{mPFC}$ alters flexible choice but does not elicit impulsive behaviors. In contrast, photoinhibition of a subset of corticocortical neurons in layer $2 / 3$ with Sepw1-Cre mice does not alter behavioral flexibility or impulsivity (Fig. $8 A$ ).

\section{The probabilistic reversal task and its relevance to OCD}

The probabilistic reversal task used in this study was designed to enable measurement of both impulsivity and behavioral flexibility in mice. Bilateral optogenetic silencing of the mPFC for short duration during the task provided independent assessments of impulsivity and behavioral flexibility in the same animal. The ability to suppress entries into the choice ports without left and right LED illumination provided a measure of behavioral inhibition. Deficits in behavioral inhibition result in impulsive responses, a central feature of OCD (Chamberlain et al., 2006; Benatti et al., 2014). Following the reversal of the side with higher reward probability, mice learn to change their responses to the appropriate port. This adjustment of behavior is a measure of cognitive flexibility that has been used in both humans and experimental animals (Chamberlain et al., 2006; Remijnse et al., 2006; Parnaudeau et al., 2013). In this study, behavioral flexibility is measured as an increase in the choice bias index defined as the difference between left and right choice probability. Increased choice bias index indicates that the decision is outcome independent and leads to suboptimal performance.

Before sessions with optogenetic stimulation, animals had experienced multiple steps of shaping and weeks of behavioral training. During this training, animals learn to form stereotypic motor sequences for performance of the task. These motor sequences are suppressed by goal-directed behavioral control in well-trained animals, but they emerge again under mPFC inactivation. Deficits in inhibiting maladaptive behaviors are commonly observed in OCD patients or OCD animal models (Chamberlain et al., 2005; Burguière et al., 2013). Because animals in the current study experience multiple shaping steps and weeks of training, it is hard to identify when the stereotypic motor sequence is formed. Future studies with behavioral paradigms requiring shorter shaping periods are needed to shed light on the direct link between behavioral observations in this study and OCD-like behaviors.

\section{Corticostriatal projection neurons}

The most prevalent circuit model for OCD involves aberrant activation of the cortico-striato-thalamocortical circuit (Berthier et al., 1996; Saxena et al., 2001). Although this model arose primarily from human neuroimaging studies, a central role for corticostriatal projection neurons in OCD-like behaviors has been supported by a series of targeted experiments in mice. For example, in Sapap3 mutant mice, downregulation of synaptic transmission at corticostriatal synapses results in excessive grooming that can be rescued by optogenetic activation of corticostriatal projections (Burguiere et al., 2013). Our observation that optogenetic silencing of corticostriatal neurons in the $\mathrm{mPFC}$ results in an increase in choice bias is consistent with that study. Further delineation of these behavioral responses and normative activity in corticostriatal neurons will be required to increase our understanding of the precise relationships between impulsivity, cognitive flexibility, and perseverative behavior.

\section{Corticothalamic projection neurons}

Human imaging studies have documented a variety of alterations in the thalamus of OCD patients, including changes in thalamic 
A

\begin{tabular}{|c|c|c|c|}
\hline Mouse line & Inhibition & Choice bias & Premature responses \\
\hline VGAT-ChR2 & All pyramidal neurons & $\uparrow$ & $\uparrow$ \\
\hline Colgalt2-cre (cell body) (ArchT) & Corticostriatal neurons & $\uparrow$ & Normal \\
\hline Colgalt2-cre (axon) (ArchT) & Corticostriatal neurons & $\uparrow$ & Normal \\
\hline Syt6-cre (ArchT) & Corticothalamic neurons & $\uparrow$ & Normal \\
\hline Sepw1-cre (ArchT) & Corticocortical neurons & Normal & Normal \\
\hline
\end{tabular}

B

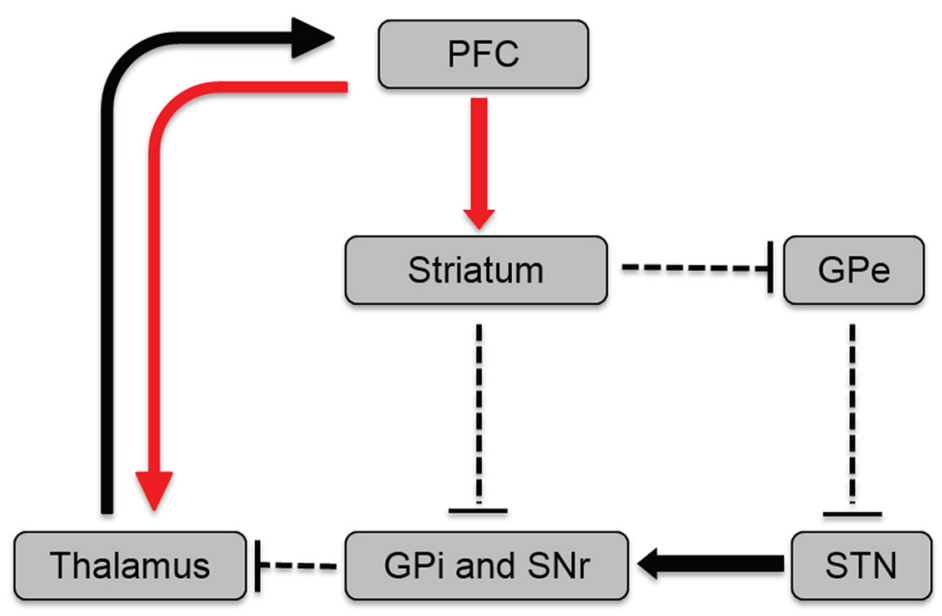

Figure 8. Summary of anatomical and genetic results and underlying circuits for behavioral flexibility. $A$, Summary of mouse lines for expression of ChR2 or ArchT in the mPFC, indicating the dominant projection area and the behavioral phenotypes induced by optogenetic stimulation during the probabilistic reversal task. $\boldsymbol{B}$, Model for the cortico-striato-thalamocortical circuit underlying behavioral flexibility. Adapted with permission from Pauls et al. (2014). Behavioral flexibility was impaired when corticostriatal and corticothalamic deep layer pyramidal neurons (red arrows) were inactivated. GPe, External globus pallidus; GPi, internal globus pallidus; SNr, substantia nigra pars reticulata.

volume (Gilbert et al., 2000; Atmaca et al., 2006) and activity (Maltby et al., 2005; Woolley et al., 2008; Gilbert et al., 2009; Del Casale et al., 2011). In this study, we have demonstrated that silencing of corticothalamic projection neurons in the $\mathrm{mPFC}$ causes a very similar phenotype to that seen in corticostriatal neurons. In both cases, we observe an increase in choice bias if the neurons are silenced during the choice period, indicating that activity in projections from the mPFC to the striatum and thalamus is required for behavioral flexibility. It is particularly noteworthy that the projections we mapped in Syt6-Cre (KI109) mice target midline thalamic nuclei, which are involved in a wide range of cognitive processes (Baxter, 2013; Parnaudeau et al., 2013; Mitchell, 2015). This raises the interesting possibility that aberrant activity in the direct projection from the $\mathrm{mPFC}$ to the midline thalamus may be an important feature of OCD. It will be of significant interest, therefore, to determine the consequences of optogenetic manipulation of corticothalamic neurons on other OCD-like behaviors.

\section{Corticocortical neurons}

Cell type-specific inactivation of layer $2 / 3$ corticocortical neurons did not induce choice bias or increased the frequency of premature responses in our studies. Given that layer 2/3 neurons project to deep layer neurons that are required for this task (DeNardo et al., 2015), this result may be counterintuitive. There are several possibilities that may underlie the different contribution of cortical layers to this behavior. The first possibility is that deep layer neurons receive redundant task-related information from different input structures and that inactivation of layer $2 / 3$ neurons makes a weaker contribution to these behaviors than inactivation of deep layer neurons. A second possibility is that the layer $2 / 3$ neurons labeled in Sepw1-Cre mice are not responsive during our behavioral task, and that deep layer neurons are driven by other inputs. In this case, inactivation of layer $2 / 3$ population will not induce similar behavioral effect as deep layer neurons even if those layer $2 / 3$ neurons project to deep layer neurons. The third possibility is that the Sepw1-Cre mouse line used in this study does not target the population of layer $2 / 3$ neurons contributing to behavioral flexibility. Future studies addressing these three possibilities will clarify the role of $\mathrm{MPFC}$ corticocortical neurons in behavioral flexibility and impulsivity.

\section{Potential cell types for impulsivity}

Numerous studies have suggested that impulse control measured as the ability to suppress undesirable movements requires the PFC and basal ganglia. However, it is not completely understood how specific cognitive processes involved in response inhibition are localized within different substructures and cell types of the PFC (Kim and Lee, 2011; Dembrow and Johnston, 2014). Here we have demonstrated that nonspecific inactivation of the MPFC leads to premature responses in the probabilistic reversal task, clearly implicating the mPFC in impulse control. However, cellspecific inactivation of the three pyramidal neuron populations in the MPFC studied here did not affect response inhibition. This may be due to involvement of cell types in the mPFC that were not targeted in this study. Additional cell types in layer 2/3 (Gerfen et al., 2013; Shrestha et al., 2015; Li et al., 2016) or layer 5 (Gradinaru et al., 2009) that were not targeted in Sepw1 or Colgalt2-Cre lines may be involved in response inhibition. For example, a subset of layer 5 neurons in the motor cortex directly project to the subthalamic nucleus (STN) (Gradinaru et al., 2009). Considering the importance of cortical afferents to the 
STN in response inhibition (Aron and Poldrack, 2006), abnormal activity of pyramidal neurons projecting to the STN may augment impulsivity. Another possibility is that inactivation of a single projection neuron class is not sufficient to alter response inhibition in this task. One might imagine, for example, that the information conveyed by either the corticostriatal or corticothalamic projections are sufficient for response inhibition in this task and that, consequently, coincident silencing of both of cell types is required to affect response inhibition.

In conclusion, our results confirm the role of corticostriatal projections in behavioral flexibility and identify corticothalamic neurons as equally important for these tasks (Fig. 7, Fig. 8). Our approach for targeting distinct population of pyramidal neurons using transgenic animals complements anatomical based targeting methods and provides us with access to otherwise inaccessible populations of neurons. Extension of this study to other genetically targeted cell types in the MPFC is an important goal. It seems evident that further delineation of circuits controlling behaviors associated with OCD in mice will complement clinical studies to provide a foundation for the development of novel strategies for therapeutic intervention.

\section{References}

Ahmari SE, Spellman T, Douglass NL, Kheirbek MA, Simpson HB, Deisseroth K, Gordon JA, Hen R (2013) Repeated cortico-striatal stimulation generates persistent OCD-like behavior. Science 340:1234-1239. CrossRef Medline

Aron AR, Poldrack RA (2006) Cortical and subcortical contributions to stop signal response inhibition: role of the subthalamic nucleus. J Neurosci 26:2424-2433. CrossRef Medline

Aron AR, Fletcher PC, Bullmore ET, Sahakian BJ, Robbins TW (2003) Stopsignal inhibition disrupted by damage to right inferior frontal gyrus in humans. Nat Neurosci 6:115-116. CrossRef Medline

Atmaca M, Yildirim BH, Ozdemirb BH, Aydinb BA, Tezcana AE, Ozlera AS (2006) Volumetric MRI assessment of brain regions in patients with refractory obsessive-compulsive disorder. Prog Neuropsychopharmacol Biol Psychiatry 30:1051-1057. CrossRef Medline

Baxter MG (2013) Mediodorsal thalamus and cognition in non-human primates. Front Syst Neurosci 7:38. CrossRef Medline

Benatti B, Dell'Osso B, Arici C, Hollander E, Altamura AC (2014) Characterizing impulsivity profile in patients with obsessive-compulsive disorder. Int J Psychiatry Clin Pract 18:156-160. CrossRef Medline

Berthier ML, Kulisevsky J, Gironell A, Heras JA (1996) Obsessivecompulsive disorder associated with brain lesions: clinical phenomenology, cognitive function, and anatomic correlates. Neurology 47:353-361. CrossRef Medline

Bolkan SS, Stujenske JM, Parnaudeau S, Spellman TJ, Rauffenbart C, Abbas AI, Harris AZ, Gordon JA, Kellendonk C (2017) Thalamic projections sustain prefrontal activity during working memory maintenance. Nat Neurosci 20:987-996. CrossRef Medline

Brakoulias V, Starcevic V, Belloch A, Brown C, Ferrao YA, Fontenelle LF, Lochner C, Marazziti D, Matsunaga H, Miguel EC, Reddy YC, do Rosario MC, Shavitt RG, Shyam Sundar A, Stein DJ, Torres AR, Viswasam K (2017) Comorbidity, age of onset and suicidality in obsessive-compulsive disorder (OCD): an international collaboration. Compr Psychiatry 76:79-86. CrossRef Medline

Buckley MJ, Mansouri FA, Hoda H, Mahboubi M, Browning PG, Kwok SC, Phillips A, Tanaka K (2009) Dissociable components of rule-guided behavior depend on distinct medial and prefrontal regions. Science 325:5258. CrossRef Medline

Bukalo O, Pinard CR, Silverstein S, Brehm C, Hartley ND, Whittle N, Colacicco G, Busch E, Patel S, Singewald N, Holmes A (2015) Prefrontal inputs to the amygdala instruct fear extinction memory formation. Sci Adv 1:e1500251. CrossRef Medline

Burguière E, Monteiro P, Feng G, Graybiel AM (2013) Optogenetic stimulation of lateral orbitofronto-striatal pathway suppresses compulsive behaviors. Science 340:1243-1246. CrossRef Medline

Burguière E, Monteiro P, Mallet L, Feng G, Graybiel AM (2015) Striatal circuits, habits, and implications for obsessive-compulsive disorder. Curr Opin Neurobiol 30:59-65. CrossRef Medline

Chamberlain SR, Blackwell AD, Fineberg NA, Robbins TW, Sahakian BJ (2005) The neuropsychology of obsessive compulsive disorder: the importance of failures in cognitive and behavioural inhibition as candidate endophenotypic markers. Neurosci Biobehav Rev 29:399-419. CrossRef Medline

Chamberlain SR, Fineberg NA, Blackwell AD, Robbins TW, Sahakian BJ (2006) Motor inhibition and cognitive flexibility in obsessive-compulsive disorder and trichotillomania. Am J Psychiatry 163:1282-1284. CrossRef Medline

Chudasama Y, Passetti F, Rhodes SE, Lopian D, Desai A, Robbins TW (2003) Dissociable aspects of performance on the 5-choice serial reaction time task following lesions of the dorsal anterior cingulate, infralimbic and orbitofrontal cortex in the rat: differential effects on selectivity, impulsivity and compulsivity. Behav Brain Res 146:105-119. CrossRef Medline

Cools R, Robbins TW (2004) Chemistry of the adaptive mind. Philos Trans A Math Phys Eng Sci 362:2871-2888. CrossRef Medline

Cools R, Clark L, Owen AM, Robbins TW (2002) Defining the neural mechanisms of probabilistic reversal learning using event-related functional magnetic resonance imaging. J Neurosci 22:4563-4567. Medline

Dalley JW, Everitt BJ, Robbins TW (2011) Impulsivity, compulsivity, and top-down cognitive control. Neuron 69:680-694. CrossRef Medline

Del Casale A, Kotzalidis GD, Rapinesi C, Serata D, Ambrosi E, Simonetti A, Pompili M, Ferracuti S, Tatarelli R, Girardi P (2011) Functional neuroimaging in obsessive-compulsive disorder. Neuropsychobiology 64:6185. CrossRef Medline

Dembrow N, Johnston D (2014) Subcircuit-specific neuromodulation in the prefrontal cortex. Front Neural Circuits 8:54. CrossRef Medline

DeNardo LA, Berns DS, DeLoach K, Luo L (2015) Connectivity of mouse somatosensory and prefrontal cortex examined with trans-synaptic tracing. Nat Neurosci 18:1687-1697. CrossRef Medline

Gerfen CR, Paletzki R, Heintz N (2013) GENSAT BAC cre-recombinase driver lines to study the functional organization of cerebral cortical and basal ganglia circuits. Neuron 80:1368-1383. CrossRef Medline

Gilbert AR, Moore GJ, Keshavan MS, Paulson LA, Narula V, MacMaster FP, Stewart CM, Rosenberg DR (2000) Decrease in thalamic volumes of pediatric patients with obsessive-compulsive disorder who are taking paroxetine. Arch Gen Psychiatry 57:449-456. CrossRef Medline

Gilbert AR, Akkal D, Almeida JR, Mataix-Cols D, Kalas C, Devlin B, Birmaher B, Phillips ML (2009) Neural correlates of symptom dimensions in pediatric obsessive-compulsive disorder: a functional magnetic resonance imaging study. J Am Acad Child Adolesc Psychiatry 48:936-944. CrossRef Medline

Gillan CM, Robbins TW (2014) Goal-directed learning and obsessivecompulsive disorder. Philos Trans R Soc Lond B Biol Sci 369:20130475. CrossRef Medline

Gong S, Doughty M, Harbaugh CR, Cummins A, Hatten ME, Heintz N, Gerfen CR (2007) Targeting Cre recombinase to specific neuron populations with bacterial artificial chromosome constructs. J Neurosci 27: 9817-9823. CrossRef Medline

Goodwin GM (2015) The overlap between anxiety, depression, and obsessive-compulsive disorder. Dialogues Clin Neurosci 17:249-260. Medline

Gradinaru V, Mogri M, Thompson KR, Henderson JM, Deisseroth K (2009) Optical deconstruction of parkinsonian neural circuitry. Science 324: 354-359. CrossRef Medline

Guo ZV, Li N, Huber D, Ophir E, Gutnisky D, Ting JT, Feng G, Svoboda K (2014) Flow of cortical activity underlying a tactile decision in mice. Neuron 81:179-194. CrossRef Medline

Han X, Chow BY, Zhou H, Klapoetke NC, Chuong A, Rajimehr R, Yang A, Baratta MV, Winkle J, Desimone R, Boyden ES (2011) A high-light sensitivity optical neural silencer: development and application to optogenetic control of non-human primate cortex. Front Syst Neurosci 5:18. CrossRef Medline

Izquierdo A, Suda RK, Murray EA (2004) Bilateral orbital prefrontal cortex lesions in rhesus monkeys disrupt choices guided by both reward value and reward contingency. J Neurosci 24:7540-7548. CrossRef Medline

Jackson SA, Horst NK, Pears A, Robbins TW, Roberts AC (2016) Role of the perigenual anterior cingulate and orbitofrontal cortex in contingency learning in the marmoset. Cereb Cortex 26:3273-3284. CrossRef Medline

Jentsch JD, Taylor JR (1999) Impulsivity resulting from frontostriatal dysfunction in drug abuse: implications for the control of behavior 
by reward-related stimuli. Psychopharmacology (Berl) 146:373-390. CrossRef Medline

Karlsson MP, Tervo DG, Karpova AY (2012) Network resets in medial prefrontal cortex mark the onset of behavioral uncertainty. Science 338:135139. CrossRef Medline

Kennerley SW, Walton ME, Behrens TE, Buckley MJ, Rushworth MF (2006) Optimal decision making and the anterior cingulate cortex. Nat Neurosci 9:940-947. CrossRef Medline

Killcross S, Coutureau E (2003) Coordination of actions and habits in the medial prefrontal cortex of rats. Cereb Cortex 13:400-408. CrossRef Medline

Kim S, Lee D (2011) Prefrontal cortex and impulsive decision making. Biol Psychiatry 69:1140-1146. CrossRef Medline

Kobayashi Y, Sano Y, Vannoni E, Goto H, Suzuki H, Oba A, Kawasaki H, Kanba S, Lipp HP, Murphy NP, Wolfer DP, Itohara S (2013) Genetic dissection of medial habenula-interpeduncular nucleus pathway function in mice. Front Behav Neurosci 7:17. CrossRef Medline

Li K, Nakajima M, Ibañez-Tallon I, Heintz N (2016) A cortical circuit for sexually dimorphic oxytocin-dependent anxiety behaviors. Cell 167:6072.e11. CrossRef Medline

Lochner C, Stein DJ (2010) Obsessive-compulsive spectrum disorders in obsessive-compulsive disorder and other anxiety disorders. Psychopathology 43:389-396. CrossRef Medline

Maltby N, Tolin DF, Worhunsky P, O'Keefe TM, Kiehl KA (2005) Dysfunctional action monitoring hyperactivates frontal-striatal circuits in obsessive-compulsive disorder: an event-related fMRI study. Neuroimage 24:495-503. CrossRef Medline

Menzies L, Chamberlain SR, Laird AR, Thelen SM, Sahakian BJ, Bullmore ET (2008) Integrating evidence from neuroimaging and neuropsychological studies of obsessive-compulsive disorder: the orbitofronto-striatal model revisited. Neurosci Biobehav Rev 32:525-549. CrossRef Medline

Miller EK, Cohen JD (2001) An integrative theory of prefrontal cortex function. Annu Rev Neurosci 24:167-202. CrossRef Medline

Mitchell AS (2015) The mediodorsal thalamus as a higher order thalamic relay nucleus important for learning and decision-making. Neurosci Biobehav Rev 54:76-88. CrossRef Medline

Monterosso JR, Aron AR, Cordova X, Xu J, London ED (2005) Deficits in response inhibition associated with chronic methamphetamine abuse. Drug Alcohol Depend 79:273-277. CrossRef Medline

Nectow AR, Moya MV, Ekstrand MI, Mousa A, McGuire KL, Sferrazza CE, Field BC, Rabinowitz GS, Sawicka K, Liang Y,Friedman JM, Heintz N, Schmidt EF (2017) Rapid molecular profiling of defined cell types using viral TRAP. Cell Rep 19:655-667. CrossRef Medline

Ostlund SB, Balleine BW (2005) Lesions of medial prefrontal cortex disrupt the acquisition but not the expression of goal-directed learning. J Neurosci 25:7763-7770. CrossRef Medline

Parker NF, Cameron CM, Taliaferro JP, Lee J, Choi JY, Davidson TJ, Daw ND, Witten IB (2016) Reward and choice encoding in terminals of midbrain dopamine neurons depends on striatal target. Nat Neurosci 19:845854. CrossRef Medline

Parnaudeau S, O'Neill PK, Bolkan SS, Ward RD, Abbas AI, Roth BL, Balsam PD, Gordon JA, Kellendonk C (2013) Inhibition of mediodorsal thalamus disrupts thalamofrontal connectivity and cognition. Neuron 77: 1151-1162. CrossRef Medline

Pauls DL, Abramovitch A, Rauch SL, Geller DA (2014) Obsessivecompulsive disorder: an integrative genetic and neurobiological perspective. Nat Rev Neurosci 15:410-424. CrossRef Medline

Peters J, Kalivas PW, Quirk GJ (2009) Extinction circuits for fear and addiction overlap in prefrontal cortex. Learn Mem 16:279-288. CrossRef Medline

Remijnse PL, Nielen MM, van Balkom AJ, Cath DC, van Oppen P, Uylings HB, Veltman DJ (2006) Reduced orbitofrontal-striatal activity on a reversal learning task in obsessive-compulsive disorder. Arch Gen Psychiatry 63:1225-1236. CrossRef Medline

Robbins TW (1996) Dissociating executive functions of the prefrontal cor- tex. Philos Trans R Soc Lond B Biol Sci 351:1463-1470; discussion 1470-1. CrossRef Medline

Rodgers CC, DeWeese MR (2014) Neural correlates of task switching in prefrontal cortex and primary auditory cortex in a novel stimulus selection task for rodents. Neuron 82:1157-1170. CrossRef Medline

Rushworth MF, Behrens TE (2008) Choice, uncertainty and value in prefrontal and cingulate cortex. Nat Neurosci 11:389-397. CrossRef Medline

Saxena S, Bota RG, Brody AL (2001) Brain-behavior relationships in obsessive-compulsive disorder. Semin Clin Neuropsychiatry 6:82-101. CrossRef Medline

Schachar R, Tannock R, Marriott M, Logan G (1995) Deficient inhibitory control in attention deficit hyperactivity disorder. J Abnorm Child Psychol 23:411-437. CrossRef Medline

Schuck NW, Gaschler R, Wenke D, Heinzle J, Frensch PA, Haynes JD, Reverberi C (2015) Medial prefrontal cortex predicts internally driven strategy shifts. Neuron 86:331-340. CrossRef Medline

Sekine Y, Minabe Y, Ouchi Y, Takei N, Iyo M, Nakamura K, Suzuki K, Tsukada H, Okada H, Yoshikawa E, Futatsubashi M, Mori N (2003) Association of dopamine transporter loss in the orbitofrontal and dorsolateral prefrontal cortices with methamphetamine-related psychiatric symptoms. Am J Psychiatry 160:1699-1701. CrossRef Medline

Shmelkov SV, Hormigo A, Jing D, Proenca CC, Bath KG, Milde T, Shmelkov E, Kushner JS, Baljevic M, Dincheva I, Murphy AJ, Valenzuela DM, Gale NW, Yancopoulos GD, Ninan I, Lee FS, Rafii S (2010) Slitrk5 deficiency impairs corticostriatal circuitry and leads to obsessive-compulsive-like behaviors in mice. Nat Med 16:598-602. CrossRef Medline

Shrestha P, Mousa A, Heintz N (2015) Layer 2/3 pyramidal cells in the medial prefrontal cortex moderate stress induced depressive behaviors. Elife 4:1-24. CrossRef Medline

Stujenske JM, Spellman T, Gordon JA (2015) Modeling the spatiotemporal dynamics of light and heat propagation for InVivo optogenetics. Cell Rep 12:525-534. CrossRef Medline

Tai LH, Lee AM, Benavidez N, Bonci A, Wilbrecht L (2012) Transient stimulation of distinct subpopulations of striatal neurons mimics changes in action value. Nat Neurosci 15:1281-1289. CrossRef Medline

Tervo DG, Proskurin M, Manakov M, Kabra M, Vollmer A, Branson K, Karpova AY (2014) Behavioral variability through stochastic choice and its gating by anterior cingulate cortex. Cell 159:21-32. CrossRef Medline

Ting JT, Feng G (2011) Neurobiology of obsessive-compulsive disorder: insights into neural circuitry dysfunction through mouse genetics. Curr Opin Neurobiol 21:842-848. CrossRef Medline

Vaghi MM, Vértes PE, Kitzbichler MG, Apergis-Schoute AM, van der Flier FE, Fineberg NA, Sule A, Zaman R, Voon V, Kundu P, Bullmore ET, Robbins TW (2017) Specific fronto-striatal circuits for impaired cognitive flexibility and goal-directed planning in Obsessive-Compulsive Disorder: evidence from resting-state functional connectivity. Biol Psychiatry 81:708-717. CrossRef Medline

Vidal-Gonzalez I, Vidal-Gonzalez B, Rauch SL, Quirk GJ (2006) Microstimulation reveals opposing influences of prelimbic and infralimbic cortex on the expression of conditioned fear. Learn Mem 13:728-733. CrossRef Medline

Welch JM, Lu J, Rodriguiz RM, Trotta NC, Peca J, Ding JD, Feliciano C, Chen M, Adams JP, Luo J, Dudek SM, Weinberg RJ, Calakos N, Wetsel WC, Feng G (2007) Cortico-striatal synaptic defects and OCD-like behaviours in Sapap3-mutant mice. Nature 448:894-900. CrossRef Medline

Winstanley CA, Eagle DM, Robbins TW (2006) Behavioral models of impulsivity in relation to ADHD: translation between clinical and preclinical studies. Clin Psychol Rev 26:379-395. CrossRef Medline

Woolley J, Heyman I, Brammer M, Frampton I, McGuire PK, Rubia K (2008) Brain activation in paediatric obsessive-compulsive disorder during tasks of inhibitory control. Br J Psychiatry 192:25-31. CrossRef Medline

Zhao S, Ting JT, Atallah HE, Qiu L, Tan J, Gloss B, Augustine GJ, Deisseroth K, Luo M, Graybiel AM, Feng G (2011) Cell type-specific channelrhodopsin -2 transgenic mice for optogenetic dissection of neural circuitry function. Nat Methods 8:745-752. CrossRef Medline 